Article

\title{
A synthetic peptide CTL vaccine targeting nucleocapsid confers protection from SARS-CoV-2 challenge in rhesus macaques
}

\author{
Paul E. Harris ${ }^{1 \#}$, Trevor Brasel ${ }^{2 \sharp}$, Christopher Massey², C. V. Herst ${ }^{3}$, Scott Burkholz 3 , Peter Lloyd ${ }^{3}$, \\ Tikoes Blankenberg, ${ }^{3,4}$, Thomas M. Bey ${ }^{4}$, Richard Carback ${ }^{3}$, Thomas Hodge ${ }^{3}$, Serban Ciotlos ${ }^{3}$, Lu

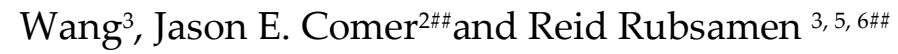

1 Department of Medicine, Columbia University, P\&S 10-502, 650 West 168th Street, New York, NY, USA 10032; peh1@cumc.columbia.edu.

2 Department of Microbiology \& Immunology, University of Texas Medical Branch, 301 University Blvd., Galveston, TX, 77555, USA; trbrasel@utmb.edu (T.Br.); jscomer@utmb.edu (J.C.); chmassey@utmb.edu (C.M.)

3 Flow Pharma Inc., 4829 Galaxy Parkway, Suite K, Warrensville Heights, OH 44128, 94523, USA; cvherst@flowpharma.com (C.H.); sburkholz@flowpharma.com (S.B.); rcarback@flowpharma.com (R.C.); thodge@flowpharma.com (T.H.); sciotlos@flowpharma.com (S.C.); lwang@flowpharma.com (L.W.); plloyd@flowpharma.com (P.L.), rrubsamen@flowpharma.com (R.R.)

4 Dignity Health Mercy Medical Center, Redding, CA, USA, 96001; docbey@gmail.com (T.Be.); teakb@aol.com (T.Bl.) 5 The Department of Anesthesiology and Perioperative Medicine, University Hospitals, Cleveland Medical Center, Case Western Reserve School of Medicine, Cleveland, OH, USA; reid.rubsamen@uhhospitals.org 6 Department of Anesthesia, Critical Care and Pain Medicine, Massachusetts General Hospital, Boston, MA, USA 02114.

\# Equal contributions

\#\# Correspondence: (R.R.) reid.rubsamen@UHHospitals.org, Tel: (216) 3508361; (J.C.) jscomer@utmb.edu, Tel:(409) 266-6915

\section{Abstract}

Background: Persistent transmission of severe acute respiratory syndrome coronavirus 2 (SARS-CoV-2) has given rise to a COVID-19 pandemic. Several vaccines, evoking protective spike antibody responses, conceived in 2020, are being deployed in mass public health vaccination programs. Recent data suggests, however, that as sequence variation in the spike genome accumulates, some vaccines may lose efficacy.

Methods: Using a macaque model of SARS-CoV-2 infection, we tested the efficacy of a peptide-based vaccine targeting MHC Class I epitopes on the SARSCoV-2 nucleocapsid protein. We administered biodegradable microspheres with synthetic peptides and adjuvants to rhesus macaques. Unvaccinated control and vaccinated macaques were challenged with $1 \times 10^{8}$ TCID50 units of 
SARS-CoV-2, followed by assessment of clinical symptoms, viral load, chest radiographs, sampling of peripheral blood and bronchoalveolar lavage (BAL) fluid for downstream analysis.

Results: Vaccinated animals were free of pneumonia-like infiltrates characteristic of SARS-CoV-2 infection and presented with lower viral loads relative to controls. Gene expression in cells collected from BAL samples of vaccinated macaques revealed a unique signature associated with enhanced development of adaptive immune responses relative to control macaques.

Conclusions: We demonstrate that a room temperature stable peptide vaccine based on known immunogenic HLA Class I bound CTL epitopes from the nucleocapsid protein can provide protection against SARS-CoV-2 infection in nonhuman primates.

Keywords: SARS-CoV-2; animal model; macaque; vaccine; MHC Class I peptide; T-cell

\section{Graphical Abstract}

PLGA microspheres containing synthetic peptide MHC Class I binding epitopes of SARS-CoV-2 nucleocapsid and CpG in MPLA vehicle

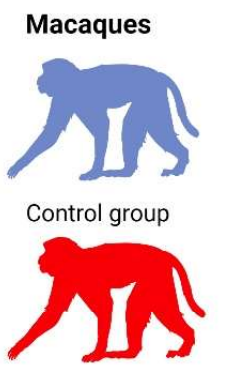

Vaccinated group

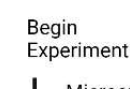

Microsphere

Prime
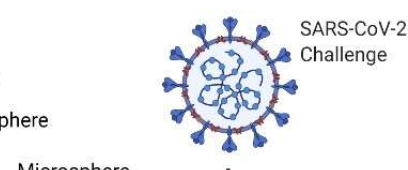

10 micron $\quad$ Microsphere phagocytosis by APC

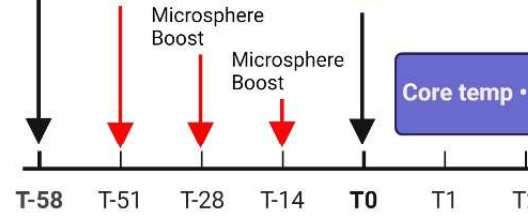
(n)

(1)
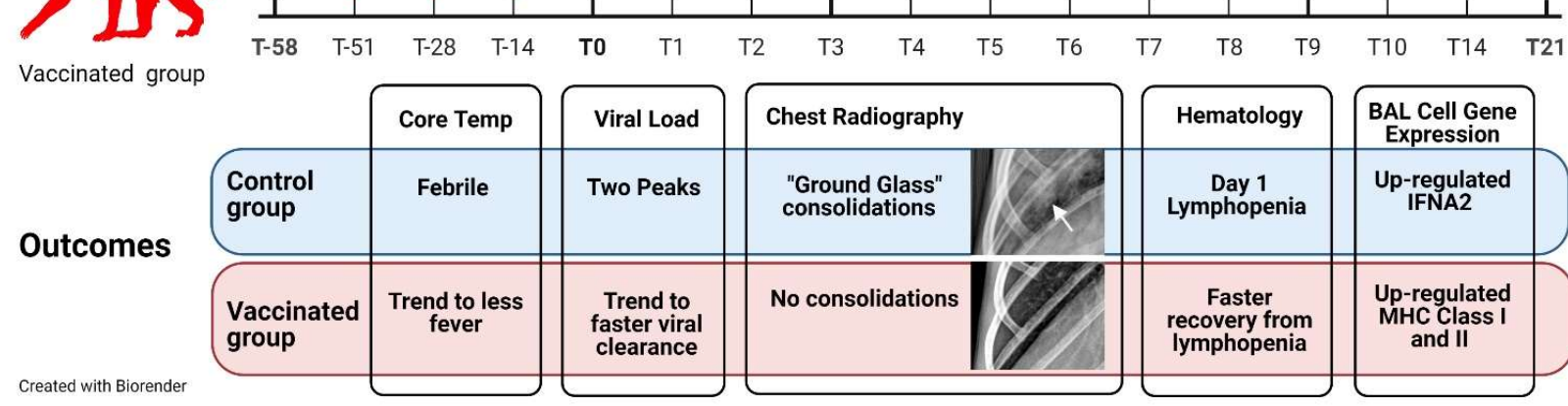


\section{Introduction}

As of April 2021, over 1.6\% of the world population have had confirmed COVID-19 disease and the new case rate is about one-half million per day. Less than $2 \%$ of the world's population are vaccinated against SARS-CoV-2[1]. Confounding efforts to reach herd immunity to COVID-19 disease include, but are not limited to the following: 1) the spread of SARS-CoV-2 mutations affecting the efficacy of current iterations of vaccines and therapeutic biologics[2], 2) the speed of SARS-CoV-2 vaccine deployment, development, and manufacture, and 3) in the context of global public health, issues related to vaccine hesitancy, cold supply chain requirements, the total manufacturing cost per dose, and ease of administration.

We have previously described a novel vaccine platform [3,4], which may address many of the above concerns and now report on its efficacy in a rhesus macaque model of SARS-CoV-2 infection. Macaque models of COVID-19 disease have been previously reported and have served as critical tools for understanding disease pathology and for the development and testing of vaccines and therapeutics [5-21]. While the clinical course of SARS-CoV-2 infection in macaques is milder relative to that observed in humans $[6,8,20,21]$, the macaque model remains the gold standard for preclinical evaluation of COVID-19 vaccines [10,19,22-27]. Our overall approach focuses on promoting protective T-cell immunity using synthetic peptides delivered in biodegradable microspheres together with Toll-like receptor (TLR) 4 and 9 adjuvants and differs from current COVID-19 vaccines against spike proteins. The synthetic peptide sequences applied are based on known immunogenic HLA Class I bound epitopes that have previously been characterized in either SARS-CoV-1 [28] or SARS-CoV-2 [29-31] infections. We provide evidence that application of this vaccine platform in SARS-CoV-2 challenged macaques provides protection from pneumonia-like pathology observed in virally challenged but unvaccinated control non-human primate (NHP) subjects, reduces viral loads as compared to unvaccinated controls, and induces changes in the gene expression patterns in recovered BAL cells consistent with enhanced antigen presentation capacity and markers of T-cells.

\section{Materials and Methods}

\section{A. Macaque MHC Class I Typing}

The MHC Class I genes of a cohort of 15 rhesus macaques (Envigo, Alice, TX, USA) were molecularly-typed by the University of Wisconsin-Madison National Primate Research Center. Mamu (Macaca mulatta) MHC class I alleles were typed amplifying the genomic DNA of each subject using a panel of specific primers for exon 2 of all known MHC-A and MHC-B alleles encoded by each subject's target DNA. Resulting amplicons were sequenced by the Illumina MiSeq method [32]. The primer panel contained specific primer pairs able to amplify all possible MHC-A and MHC-B alleles encoded by each macaque. Sequencing data analysis provided a high-resolution haplotype for the MHC-A and MHC-B alleles carried by each subject. Following analysis, we selected four of the 15 macaques for vaccination based on peptide MHC binding predictions as described below.

\section{B. Vaccine Design/Peptide Selection and Manufacture}


In silico design and selection of SARS-CoV-2 CTL epitopes.

The overall strategy and rationale used in the selection of synthetic peptides used to stimulate potential CTL immune responses in SARS-CoV-2 infected humans has been previously described $[3,4]$. We selected SARS-CoV-2 nucleoprotein as the target of CTL attack based on the following rationale: 1) survivors of SARS-CoV-1 have shown a memory T-cell response to nucleoprotein at least 2 years after infection [28], 2) there is $>90 \%$ amino acid sequence homology between SARS-CoV- 1 and SARSCoV-2 nucleoprotein (the homology for the selected CTL epitopes used in this report is 100\%) [33], and 3) in general, there is a lower frequency of mutations resulting in amino acid substitutions (relative to Spike protein) that might affect the immunogenicity of the selected CTL epitopes represented by synthetic peptides within the vaccine formulation [34]. The lower mutation frequency may reflect the hypothesis that amino acid substitutions in nucleoprotein may impact viral fitness [35]. We reviewed previous literature and MHC peptide-binding databases [36] and selected five amino sequences representing SARS-CoV-2 nucleoprotein with predicted strong in vitro affinity for HLA Class I molecules[37], and/or documented or predicted immunogenic potential[4,28-31,33,38,39]. Together this set of peptides yielded potential broad coverage of HLA haplotypes ( $>90 \%$ worldwide) (Supplemental data, Table S1A). The predicted binding of this set of peptides was examined within the MHC genotypes of the cohort of 15 rhesus macaques [40] available to us and the best correspondence between selected peptides and rhesus MHC Class I genotype was selected (Supplemental data, Table S1B). Because the predicted peptide macaque MHC binding coverage for the peptide LLLDRLNQL was incomplete in the available genotypes, we added an additional peptide (ASAFFGMSR) with predicted strong Mamu MHC Class I binding to the formulation for a total of six peptides.

\section{Microsphere preparation and adjuvant formulation}

The peptide epitopes used in this study were delivered in vivo by intratracheal instillation of a formulation of Poly-L-lactide-co-glycolide (PLGA) microspheres containing the corresponding synthetic nine-mer peptides and TLR-9 agonist $\mathrm{CPG}$ oligonucleotide adjuvant in a vehicle containing TLR-4 agonist monophosphoryl lipid A (MPLA). The rationale for the choice of the delivery platform and the basic manufacturing scheme used in production has been previously reported [3,4,41]. Briefly, room temperature solutions of a synthetic peptide, $\mathrm{CpG}$ oligonucleotide, and mannose were mixed with a solution of PLGA in acetone/water followed by sonication. The formulation was then processed through a precision spray-drying device (Buchi Corporation, New Castle, DE, USA) and passed through a drying chamber (air at room temperature) to allow evaporation of the acetone. The dry microsphere stream was analyzed in real-time through a laser particle size analyzer (SprayTech, Malvern Instruments, Malvern, PA) before collection (Buchi cyclone drier) as a dry powder for reconstitution at the time of delivery using a $2 \%$ DMSO aqueous solution containing MPLA (20 $\mu \mathrm{g} / \mathrm{ml}$ ). Each microsphere contained peptide loaded at approximately $0.1 \%$ by weight and $\mathrm{CpG}$ $0.01 \%$ by weight. Monitoring of the microsphere diameters allowed the production of microspheres with a mean diameter of $10 \pm 2$ microns. This diameter was selected for formulation to ensure delivery via phagocytosis of no more than 1-4 microspheres per antigen-presenting cell (APC) which have an average diameter of 13 microns [3]. cGMP manufacturing protocols were employed using GMP grade synthetic peptides (Peptides International, Louisville, KY, USA), CpG oligonucleotides 
(Trilink Biosciences, San Diego, CA, USA), and MPLA (Avanti Polar Lipids, Alabaster, AL, USA). The CpG oligonucleotide and MPLA used in this study were manufactured using the same chemical compositions as equivalent materials used in FDA-approved vaccines. Assessment of thermal stability of the synthetic peptides within the microspheres has been previously reported [3]. Peptide content and structure in microspheres were determined by HPLC after two months of room temperature storage. We found that over $99 \%$ of the peptide was maintained structurally intact (data not shown).

\section{Animal Studies}

\section{Ethics statement}

The animal research protocols used in this study were performed in strict accordance with the recommendations in the Guide for Care and Use of Laboratory Animals, Eighth Edition (National Academy Press, Washington, D.C., 2011). The University of Texas Medical Branch (UTMB) facility where these studies were conducted is accredited by the Association for Assessment and Accreditation of Laboratory Animal Care. The protocols were approved by the UTMB Institutional Animal Care and Use Committee (Protocol Numbers 2004051 [natural history/control study] and 2003033 [vaccination study]) and complied with the Animal Welfare Act, the U.S. Public Health Service Policy, and other Federal statutes and regulations related to animals and experiments involving animals. All hands-on manipulations, including immunizations and biosampling, were performed while animals were sedated via ketamine $(5 \mathrm{mg} / \mathrm{kg}) / \mathrm{dexmedetomidine}(0.025 \mathrm{mg} / \mathrm{kg})$ intramuscular injection. All efforts were made to minimize suffering.

\section{Macaques}

Adult Indian origin rhesus macaques (Macaca mulatta, $\mathrm{n}=7$ [ 5 male, 2 female], 46-48 months old) or Vietnamese origin cynomolgus macaques (Macaca fascicularis, $\mathrm{n}=1$ female, 84 months old), individually identified via unique tattoo, were obtained from Envigo/Covance (Alice, Texas, USA). All animals were considered healthy by a veterinarian before being placed on study. Macaques were individually housed in stainless steel nonhuman primate caging equipped with squeeze backs for the duration of the studies. For continuous core body temperature measurements, a DST micro-T implantable temperature logger (Star-Oddi, Gardabaer, Iceland) was surgically implanted into the peritoneal cavity of each animal prior to study initiation; data recording was set to 10- or 15-min intervals for control and vaccinated macaques, respectively. Certified primate Diet 5048 was provided to the macaques daily. Drinking water $(\mathrm{RO})$ was provided ad libitum through an automatic watering system. To promote and enhance the psychological well-being of the animals, food enrichment consisting of fresh fruits and vegetables was provided daily. Environmental enrichment including various manipulatives (Kong toys, mirrors, and puzzles) was also provided.

\section{Immunization, Virus Challenge, Post-Challenge Monitoring and Biosampling}

\section{Immunization and ELISPOT analysis}

Immunizations were performed on the selected MHC-typed rhesus macaques $(n=4)$ via ultrasound-guided inguinal lymph node injection (LN) and/or intratracheal instillation (IT). Twenty mg 
of vaccine microsphere preparation in $1 \mathrm{ml}$ was used for each LN injection (two injections / dose / animal) and 100mg of vaccine microspheres in a $5 \mathrm{ml}$ volume was used for each IT administration. Specifically, on Day -51 (51 days prior to virus challenge), two of the macaques (Figure 1) were administered $2 \mathrm{~mL}$ of vaccine via $\mathrm{LN}$ injection ( $1 \mathrm{~mL}$ per node). Subsequent administration of the vaccine occurred via the IT route $(5 \mathrm{~mL})$ only as described previously[42]. Remaining vaccine doses, administered on Days - 28 and -14, were delivered via IT only ( $5 \mathrm{~mL}$ per dose) to the rhesus vaccination group. On Days $-44,-21$, and -7 (7 days post-vaccination), femoral vein peripheral blood $(8 \mathrm{~mL})$ was collected from each animal into a BD Vacutainer ${ }^{\circledR}$ CPT ${ }^{\mathrm{TM}}$ Cell Preparation Tube with Sodium Heparin (Becton, Dickinson and Company, Franklin Lakes, NJ, USA) and processed to peripheral blood mononuclear cells (PBMCs) per manufacturer instructions. Collected PBMCs were assessed for immunoreactivity via ELISPOT. In brief, ELISPOT assay plates (MabTech Inc., Cincinnati, OH, USA) specific for the detection of primate IFN $\gamma$ were used according to manufacturer instructions. BAL cell concentrations were adjusted to $1 \times 10^{5}$ cells per $\mathrm{mL}$ in a complete growth medium. Diluted BAL cells were dispensed $(100 \mu \mathrm{L} /$ well) into a 96 -well plate after which $100 \mu \mathrm{L}$ of complete growth medium (CGM, negative control), Concanavalin A in CGM at $10 \mu \mathrm{g}$ per well (positive control), and various concentrations of specific (i.e., immunizing) and non-specific peptides (Supplemental data, Table S1B) were added. Peptides used for immunization were added to wells at a concentration of $50 \mu \mathrm{M}$. All samples were assayed in duplicate. Plates were incubated at $37^{\circ} \mathrm{C} / 5 \% \mathrm{CO}_{2}$ for $20-22$ hours after which plates were thoroughly washed. Conjugated detection antibody was then added and incubated followed by additional washing. Wells were developed

\section{Figure 1}

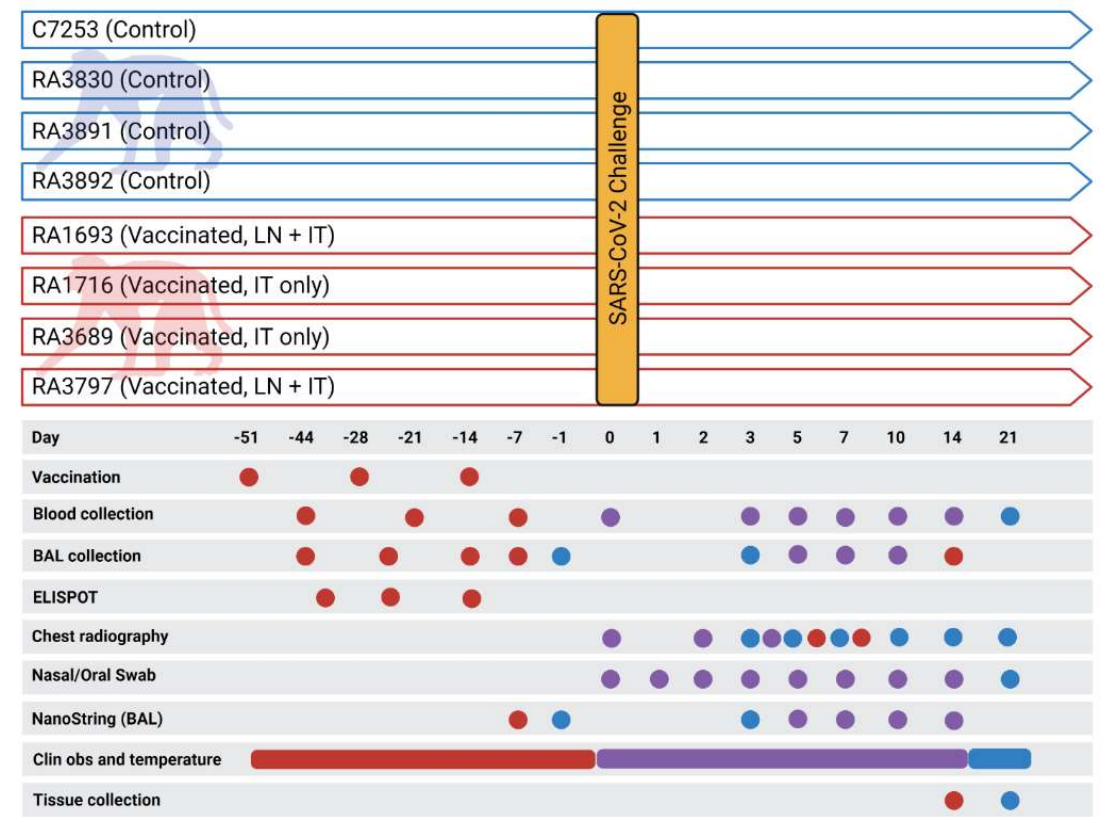

Figure 1 Legend. Schematic of the experimental protocol. Unvaccinated (control) macaques are represented by blue coloring. Vaccinated macaques are represented by red coloring. Overlapping tasks are represented by purple coloring. Graphic created with BioRender.com. 
using TMB as a substrate. Counts were performed at Cellular Technology Corporation (Shaker Heights, OH, USA) using an Immunospot Analyzer and all well images were quality-controlled on site. All spot-forming cell counts reported are the result of averaging counts from the duplicate $50 \mu \mathrm{M}$ immunization-specific peptide wells.

\section{Virus challenge}

On Day 0, macaques were administered 1-5 ×108 TCID50 SARS-CoV-2 (USA_WA1/2020) via combined mucosal atomization $\left(1 \mathrm{~mL}\right.$ as delivered using a MAD Nasal ${ }^{\mathrm{TM}}$ Intranasal Mucosal Atomization Device per manufacturer instructions) and intratracheal instillation (4 mL). Intratracheal instillations were performed as described above for delivery of the vaccine. The virus suspension was prepared on the day of challenge from frozen seed stock (kindly provided by Dr. Chien-Te [Kent] Tseng at UTMB) initially generated (one passage) in Vero C1008 (E6) cells (BEI Resources, NR-596, Lot 3956593) from original material provided by the Centers for Disease Control and Prevention in January 2020. Next-generation sequencing confirmed a 100\% consensus sequence-level match to the original patient specimen (GenBank accession MN985325.1).

\section{Post-challenge monitoring and chest radiography}

Animals were monitored and scored twice daily for clinical signs of disease including alterations in activity/appearance (i.e., hunched posture), food consumption/waste output, and were scored based on general appearance, activity, food consumption, and outward changes in breathing patterns. Prospectively defined criteria that required immediate euthanasia included severe dyspnea and/or agonal breathing and prostate posture/reluctance to move when stimulated. No animals met endpoint criteria during the study. Ventrolateral chest radiography was performed on the days indicated (Figure 1) using a portable GE AMX-4+ computed radiography system per manufacturer instruction. DICOM data files were independently evaluated by two independent investigators blinded to group assignment with large animal imaging experience via a four-pattern approach (analyses of consolidation, interstitial areas, nodules or masses, and atelectasis).

\section{Biosampling}

Blood, nasal cavity samples, and BAL fluid were collected at the indicated times (Figure 1). Femoral vein peripheral blood was collected via Vacutainer ${ }^{\circledR}$ into standard collection tubes containing ethylenediaminetetraacetic acid (EDTA). Hematology was performed on EDTA blood using the Abaxis VETSCAN® HM5 Hematology Analyzer (Abaxis, Inc., Union City, CA, USA). Nasal cavity samples, collected using sterile cotton-tipped medical swabs, were placed into $0.5 \mathrm{~mL}$ sterile phosphate-buffered saline (PBS) for viral load analysis. For BAL fluid collection, animals were sedated as previously described and placed in ventral recumbency. The trachea was visualized and cannulated by an appropriately sized rubber feeding tube. Following the placement of the feeding tube, $20 \mathrm{~mL}$ of sterile PBS was introduced into the lung and recovered manually through the feeding tube via syringe. This was repeated for a total of $40 \mathrm{~mL}$ per animal. The total collected volume from each animal $(10-30 \mathrm{~mL})$ was pooled and centrifuged under ambient conditions (10 min at $500 \mathrm{xg})$ after which the supernatant was removed. The resulting cell pellet was resuspended in $2 \mathrm{~mL}$ of sterile PBS. From this, $1 \mathrm{~mL}$ was used for ELISPOT analysis as described for PBMCs. The remaining volume was used for viral load analysis and gene expression profiling. 


\section{E. Viral Load Analysis}

Infectious viral load (TCID 50 )

Nasal swab and BAL cells suspension samples were serially diluted and incubated with $2 \times 10^{4}$ Vero C1008 (E6) cells (BEI Resources, NR-596, Lot 3956593) in $100 \mu \mathrm{l}$ of culture medium (MEM/2\% FBS) in 96-well flat-bottom plates ( $n=5$ replicate wells per dilution). Each plate contained negative and positive control wells inoculated with culture medium and diluted virus stock, respectively. Cultures were incubated at $37^{\circ} \mathrm{C} / 5 \% \mathrm{CO} 2$ for $96 \mathrm{~h}$ after which cytopathic effect was measured via microscopic observation. The TCID $50 / \mathrm{mL}$ value for each sample was calculated as previously described[43]. Macaque C75243 (cynomolgus) was not included in this study.

\section{$q R T-P C R$}

Nasal swab and BAL cell suspension samples $(50 \mu \mathrm{L})$ were added to TRIzol® LS Reagent $(250 \mu \mathrm{L})$ and allowed to incubate under ambient conditions for $10 \mathrm{~min}$. Samples were processed to RNA using Zymo Direct-zol ${ }^{\mathrm{TM}}$ RNA Mini Prep kits per manufacturer instructions. RNA samples were analyzed via qRT-PCR targeting the SARS-CoV-2 E gene. Probe (Integrated DNA Technologies, Coralville, IA, USA) was labeled at the $5^{\prime}$-end with fluorophore 9-carboxyfluoroescein (6-FAM) and included an internal quencher (ZEN) and a 3'-end quencher (IowaBlackFQ, IABkFQ). Master Mix was prepared by combining forward primer $\left(250 \mathrm{nM}, 5^{\prime}\right.$-ACAGGTACGTTAATAGTTAATAGCGT$\left.3^{\prime}\right)$, reverse primer $\left(250 \mathrm{nM}, 5^{\prime}\right.$-ATATTGCAGCAGTACGCACACA-3'), and probe $\left(375 \mathrm{nM}, 5^{\prime}\right.$ 6FAM-ACACTAGCC/ZEN/ATCCTTACTGCGCTTCG-IABkFQ-3') with $12.5 \mu \mathrm{L}$ of 2 X QuantiFast Probe Mix (QIAGEN), $0.25 \mu \mathrm{L}$ of $2 X$ QuantiFast RT Mix (QIAGEN), and PCR-grade water (fill to 20 $\mu \mathrm{L})$. To the Master Mix, a test sample $(5 \mu \mathrm{L})$ was added resulting in a final volume of $25 \mu \mathrm{L}$ per reaction. Real-time analysis was performed using the Bio-Rad CFX96 ${ }^{\mathrm{TM}}$ Real-Time PCR Detection System. Thermocycling conditions were as follows: Step 1,1 cycle, $50^{\circ} \mathrm{C}$ for 10 minutes; Step 2, 1 cycle, $95^{\circ} \mathrm{C}$ for 10 minutes; Steps $3-5,45$ cycles, $95^{\circ} \mathrm{C}$ for 10 seconds, $60^{\circ} \mathrm{C}$ for 30 seconds, single read. Negative controls included reaction mixtures without RNA. For quantification purposes, viral RNA extracted from the virus seed stock with a known TCID $5 / \mathrm{mL}$ titer was used. All qRT-PCR results are expressed as TCID $50 / \mathrm{mL}$ equivalents. Macaque $\mathrm{C} 75243$ (cynomolgus) was not included in this study.

\section{F. Gene Expression Profiling}

BAL samples were processed to RNA as described above for qRT-PCR analysis. RNA quantity and quality were assessed using a NanoDrop ${ }^{\mathrm{TM}}$ Lite Spectrophotometer (ThermoFisher Scientific, Waltham, MA, USA). Samples, normalized to $20 \mathrm{ng} / \mu \mathrm{L}$, were analyzed by NanoString Technologies (Seattle, WA, USA) using the nCounter ${ }^{\circledR}$ SPRINT ${ }^{\mathrm{TM}}$ Profiler gene expression profiling using the NonHuman Primate Immunology V2 Panel containing 754 genes that encompass 17 immune-related signaling pathways with isoform coverage for both Macaca mulatta and Macaca fascicularis. Probe sets that did not cover both Macaca species were eliminated resulting in a probe set of 730 genes. Raw gene expression data sets received from NanoString Technologies were processed to remove background signals and normalized using the nSolver ${ }^{\mathrm{TM}}$ V.3.0 digital analyzer software. Background signal correction was accomplished by subtracting the NanoString negative control genes. 
Gene expression normalization was performed using the 16 internal reference genes included in the panel.

\section{G. Study Termination}

At scheduled study termination time points (14 and 21 days post-challenge for vaccinated and control macaques, respectively), animals were humanely euthanized via intravenous administration of a pentobarbital-based euthanasia solution under deep anesthesia followed by bilateral thoracotomy.

\section{H. Statistical Analysis}

Descriptive statistics were performed using Microsoft Excel. Hypothesis testing was performed by considering the null hypothesis of the absence of an association between the compared variables. The statistical strength of associations of continuous data was tested using Students $t$-testing. Qlucore Omics Explorer 3.5 (Qlucore), Metascape (Metascape.org) was used to identify the discriminating variables within the NanoString gene expression data sets from BAL sample analysis that were most significantly different between vaccinated and control subjects. The identification of significantly differential variables between the two groups was performed by fitting a linear model for each variable. The set of genes (87 variable genes out of a total of 730 genes) was identified using a p-value of 0.05 , at least a three-fold change, and a q-value cutoff of 0.1 . P-values were adjusted for multiple testing using the Benjamini-Hochberg method [44]. Gene expression data were scaled to a mean $=0$ and a variance $=1$ before clustering. Hierarchical clustering of gene expression in BAL was performed using a supervised weighted average linkage two comparisons approach. The metric used in scaling dendrogram arms was Pearson's correlation coefficient.

\section{Results}

\section{A. Primary Clinical Outcomes}

Clinical signs, body temperature alterations and hematology.

Following SARS-CoV-2 challenge, outward clinical signs measured in control macaques included acute mild lethargy and respiratory distress. All vaccinated animals were normal throughout the post-challenge study period. Core body temperatures, as measured via implanted Star-Oddi DST temperature loggers, demonstrated a disruption in the diurnal cycle and mild fever lasting 2-5 days post-challenge in all four-control animals (Figure 2, top panels). Conversely, only two of the four vaccinated macaques (RA1693 and RA3797) presented with similar findings, although diurnal cycle disruption was of shorter duration (1-2 days) and the febrile response was milder (Figure 2, bottom panels). No alterations were measured in the remaining two vaccinated animals. Prior to virus challenge, vaccinated macaques presented with occasional disruptions in the diurnal temperature associated with the vaccination procedure (Supplemental Data, Figure S1).

Automated hematology analyses were performed on peripheral blood samples (Supplemental Data, Figure S2). Overall, the number of white blood cells was significantly increased in control 


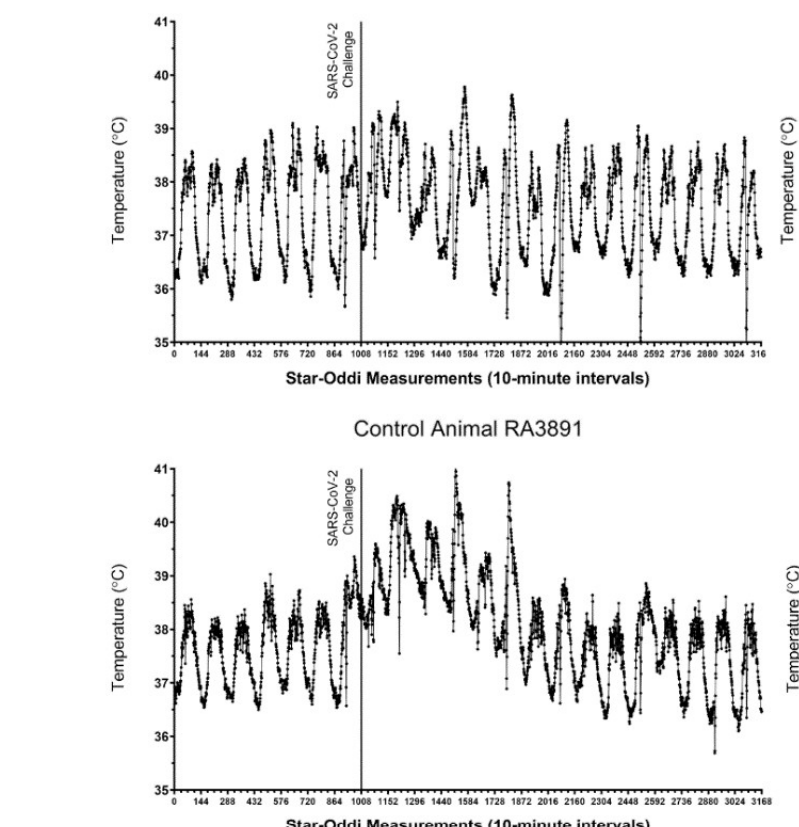

Vaccinated Animal RA3689
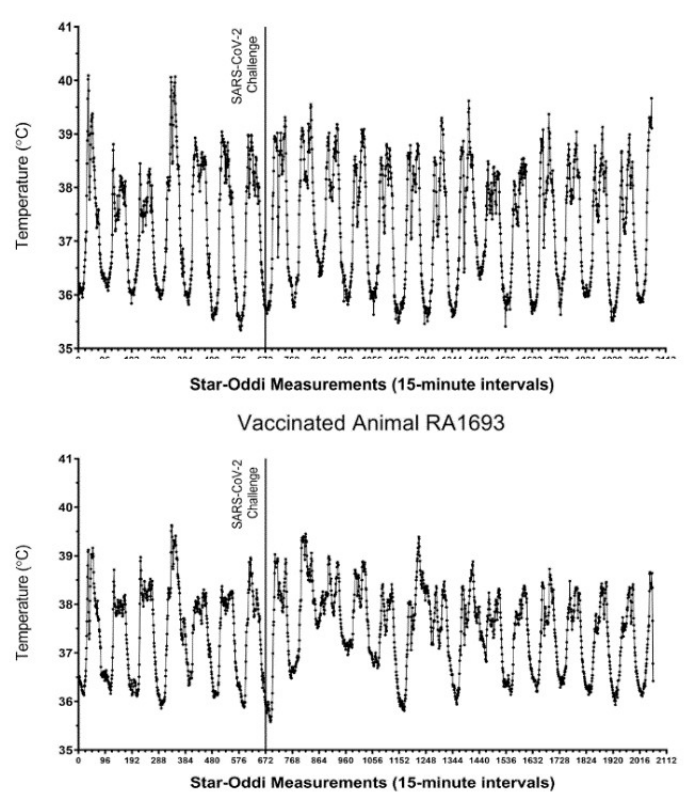

Control Animal RA3830
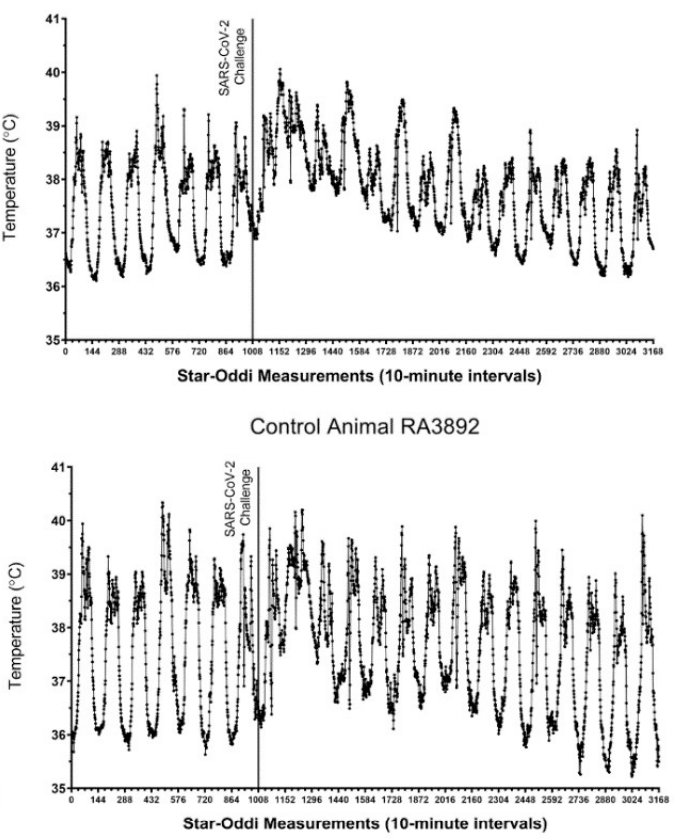

Vaccinated Animal RA1716
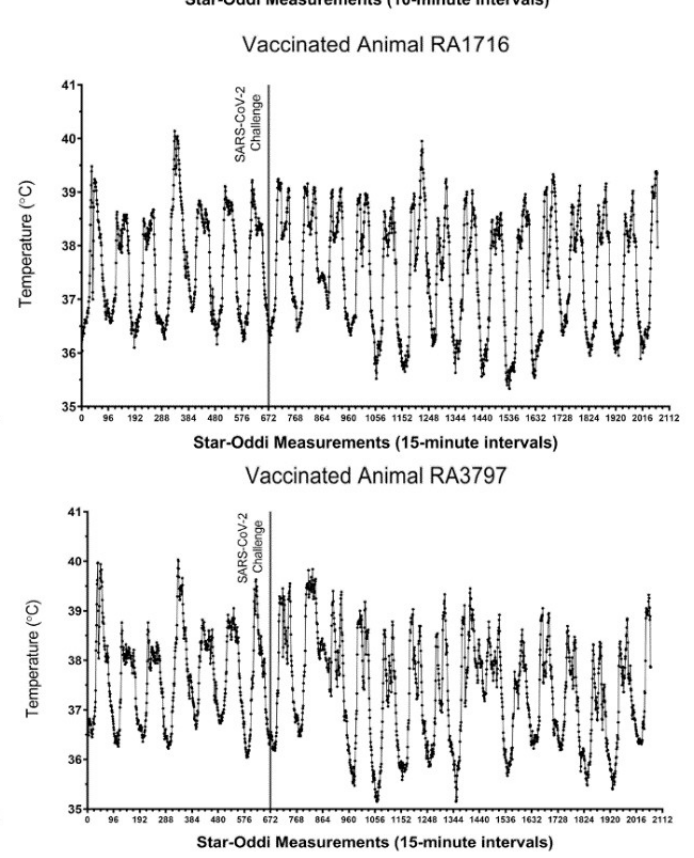

\section{Figure 2}

Figure 2 Legend. Core body temperature alterations in control and vaccinated macaques following SARS-CoV-2 challenge. For each animal, seven days of pre-challenge baseline temperature measurements are shown. Each tick on the x-axis represents 6 hours or 36 individual logger measurements. 
subjects on post-challenge days 3 and 5. We observed general lymphopenia in all macaques on day 1 post-challenge. By day 3 post-challenge, lymphocyte counts significantly increased in vaccinated subjects relative to unvaccinated control subjects. Peripheral blood monocyte counts generally peaked on days 1 through 5 in all animals but remained significantly elevated in vaccinated macaques at the end of the study. Neutrophil counts generally rose by day 1 post-challenge in all subjects. There was a transient significant elevation in neutrophils on day 7 post-challenge in vaccinated animals.

\section{Viral load}

Following SARS-CoV-2 challenge, nasal swab and BAL fluid samples were collected throughout the post-challenge period for analysis of infectious viral load and viral RNA via TCID50 and qRT-PCR assays, respectively. Infectious virus was measured from nasal swabs of control and vaccinated macaques beginning one-day post-challenge (Figure 3 [top panel]). By Day 7, 3 of the 4 unvaccinated animals continued to demonstrate infectious viral shedding, albeit at low levels. In contrast, infectious virus could be measured in only one of the vaccinated macaques at the same time point. By 10 days post-challenge, infectious viral loads were undetectable in nasal swab samples from all animals. Viral RNA in nasal swabs generally reflected infectious viral loads. By Day 7, three of the four vaccinated animals demonstrated a 100-fold decrease in nasal swab viral RNA relative to the unvaccinated controls (Figure 3 [bottom panel]). By 14 days post-challenge, SARS-CoV-2 RNA levels were undetectable in nasal swab samples from all subjects. Infectious viral load data were used to calculate an average viral clearance rate post-challenge for each rhesus macaque. The average viral clearance rate from Days 2 through 10 was 4-5 fold higher in two of the four vaccinated macaques (RA1693 and RA3797) relative to the unvaccinated controls (Supplemental data, Figure S3).

\section{Macaque chest radiography}

SARS-CoV-2 challenge in unvaccinated controls resulted in mild-to-moderate lung abnormalities, similar to those previously reported for macaques $[6,15,16,20,45-48]$. These were predominantly limited to the caudal lung relative to baseline images, peaked 3-5 days post-challenge, and were qualitatively characteristic of subclinical or mild-to-moderate human COVID-19 (e.g., ground-glass opacities with or without reticulation, paving, silhouetting, and/or linear opacities). The mild to moderate interstitial pneumonitis seen on the ventrolateral chest radiographs of unvaccinated subjects are consistent with focal infiltrates representing a complex of interstitial macrophages, neutrophils, and plasmacytoid dendritic cells [49]. Abnormalities in control animals resolved by Days 10-21. In contrast, vaccinated macaques lacked the appearance of ground-glass opacities in all regions of the lung throughout the study period (Figure 4 and Supplemental data, Figures S4-S9). We did observe, however, modest bilateral increases in reticulation in vaccinated macaques on Days 3-5, but these abnormalities also resolved by Day 10-21. Bronchoalveolar lavage has been reported to affect computerized tomography X-ray results in healthy rhesus macaques [50]. In our study, however, the pattern of reported changes in vaccinated (i.e., healthy) animals on which BAL was performed was more similar to increases in reticulation versus the patchy consolidations observed in the unvaccinated controls. 


\section{Figure 3.}
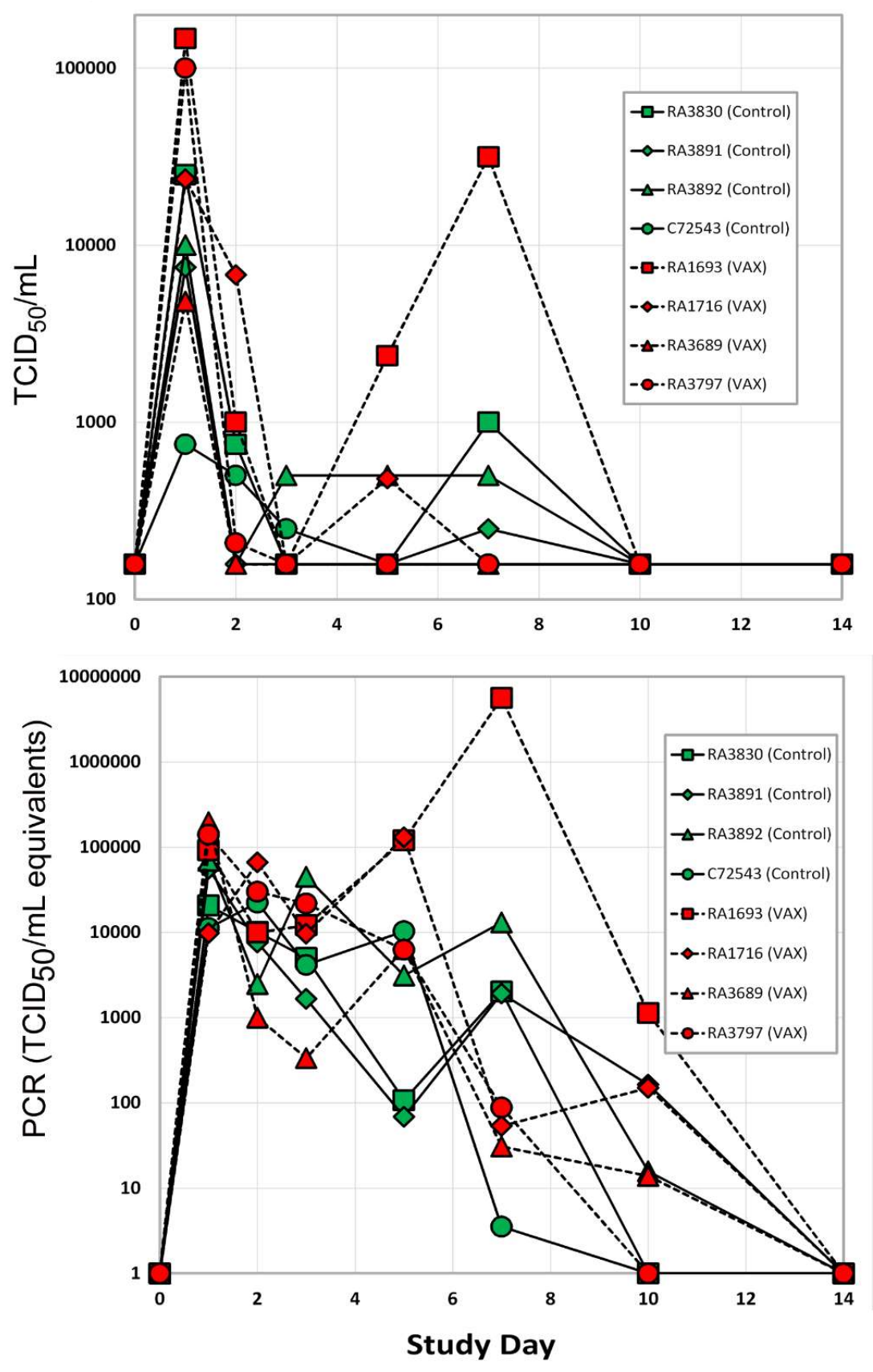

Figure 3 legend. Viral load in nasal swab samples as measured via TCID 50 assay (top) and qRTPCR (bottom). The LLOD of the plaque assay was 150 units. Red symbols are vaccinated rhesus macaques, control unvaccinated rhesus subjects are shown in green symbols. 
Figure 4

\section{Unvaccinated}
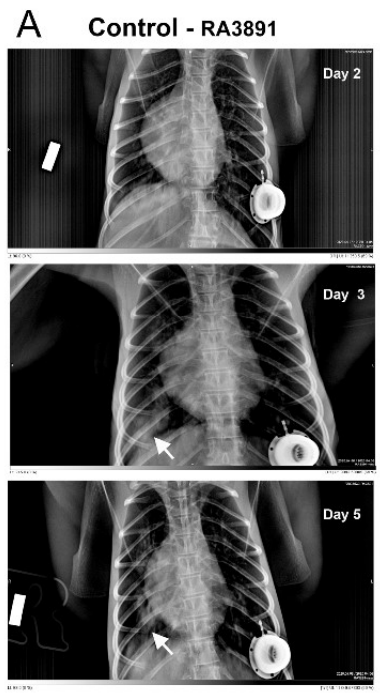

B Control - RA3830
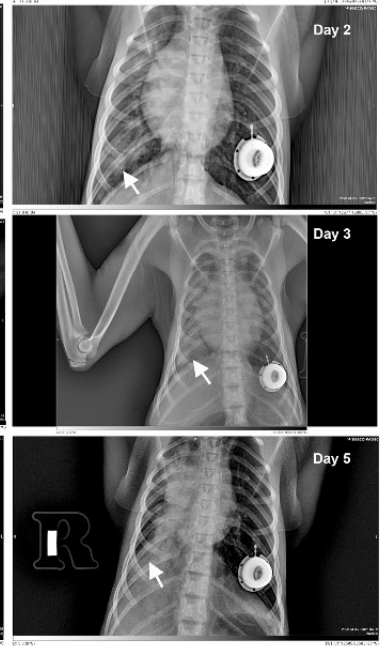
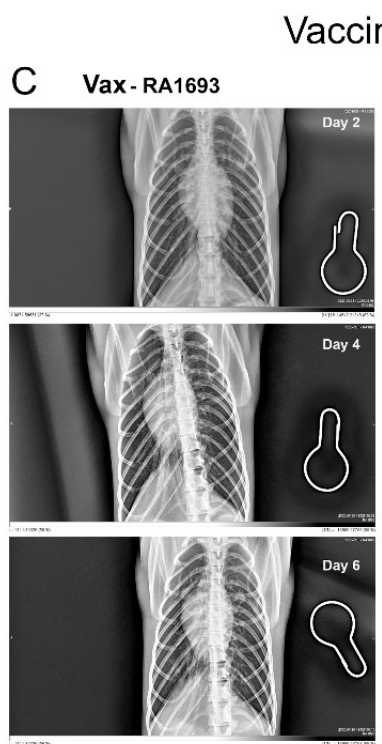
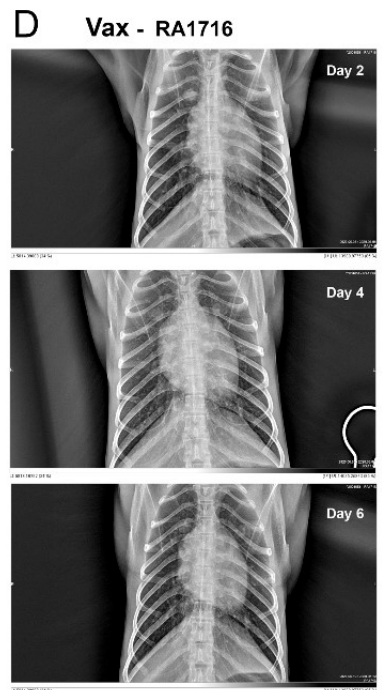

Figure 4 Legend. Representative chest radiographs of control and vaccinated macaques following SARS-CoV-2 challenge. As shown, control macaques (left columns A and B) demonstrated a progression of pulmonary infiltrates during the acute period (Days 2-5) of disease post-challenge. In contrast, vaccinated macaques (right columns $C$ and $D$ ) lacked similar abnormalities. White arrows indicate areas of mild to moderate pulmonary infiltrates seen as ground glass consolidations. 


\section{B. Secondary Outcomes}

Analysis of gene expression patterns in BAL cells

We identified a set of 87 genes in BAL samples collected 5-7 days post-challenge from control animals with statistically significant differential expression (as measured from changes in accumulation of their specific transcripts) versus BAL samples collected from vaccinated animals during the same time points (Figures 5 and 6). We selected to focus on the Day 5 and Day 7 samples to capture a possible peak of adaptive immune responses to SARS-CoV-2 challenge as suggested by previous reports [51,52]. Several of the identified differentially regulated genes were of particular interest in the context of adaptive viral $\mathrm{T}$ cell immunity (Tables 1 and 2). Several differentially regulated immune response genes laying outside the main window of interest (i.e., Day 5 alone, Day 7 alone, or Day 10 alone) were also identified (Tables 1 and 2 and Supplemental data, Figure S10). For example, on Day 5 in unvaccinated macaques, we found up-regulation of IFIT3 and IL-1RAP. The expression levels of these transcripts have been previously reported to correlate with viral loads in a SARS-CoV-2 rhesus macaque model of COVID-19 disease [5].

In BAL samples collected on Days 5 and 7, we observed statistically significant up-regulation of MHC Class I genes, MHC Class II and associated accessory genes (CD74 invariant chain, HLA-DM), and T cell markers (CD8 and IL2) in the vaccinated group relative to the unvaccinated control macaques. We also observed statistically significant down-regulation of Interferon alpha 2 (IFNA2), the negative regulator of T cell expansion, PD-L1, the decoy receptor for IL1 $\alpha$ and IL1 $\beta$ inhibiting signaling, and FoxJ1, a regulator of Th1 cell activation [53] in the vaccinated group relative to the unvaccinated control macaques.. This pattern suggests enhanced antigen presentation and CD 4/8+ $\mathrm{T}$ cell response capacity in BAL cells from vaccinated macaques relative to the controls. In control animals, we observed up-regulation of several genes (CCR1, CSF3R, IFNA2, IL-1RN, IL-1RAP, IL$1 \mathrm{R} 2$, and SOXS3) previously reported to be activated during SARS-CoV-2 infection in rhesus macaques [5]. These genes appeared to be down-regulated, relative to controls, in vaccinated macaques.

The vaccine formulation containing synthetic peptide cytotoxic T cell epitopes, $\mathrm{CpG}$, and MPLA adjuvants was delivered primarily via intratracheal instillation. While we did not observe any adverse clinical signs of respiratory distress in vaccinated subjects, we examined BAL cell gene expression for lymphokines and cytokines associated with the observed mixed Th1/Th2 patterns observed in asthma [54] (Supplemental data, Figures S11 and S12). In BAL samples collected on Days 5 and 7, we did not observe significant differences in expression of IL4, IL5, IL6, IL9, IL10. IL13, CXCL10, CCL5, CCL7, CCL22, CX3CL1, or CXCL1. We did observe a general trend of higher expression for many of the cytokines in BAL cell samples collected from vaccinated macaques prechallenge compared to unvaccinated pre-challenge controls. This effect was generally transient, diminishing by Day 5 post-challenge. This pattern of cytokine and lymphokine expression did not suggest that BAL cells assumed a phenotype associated with a Th2 response. 


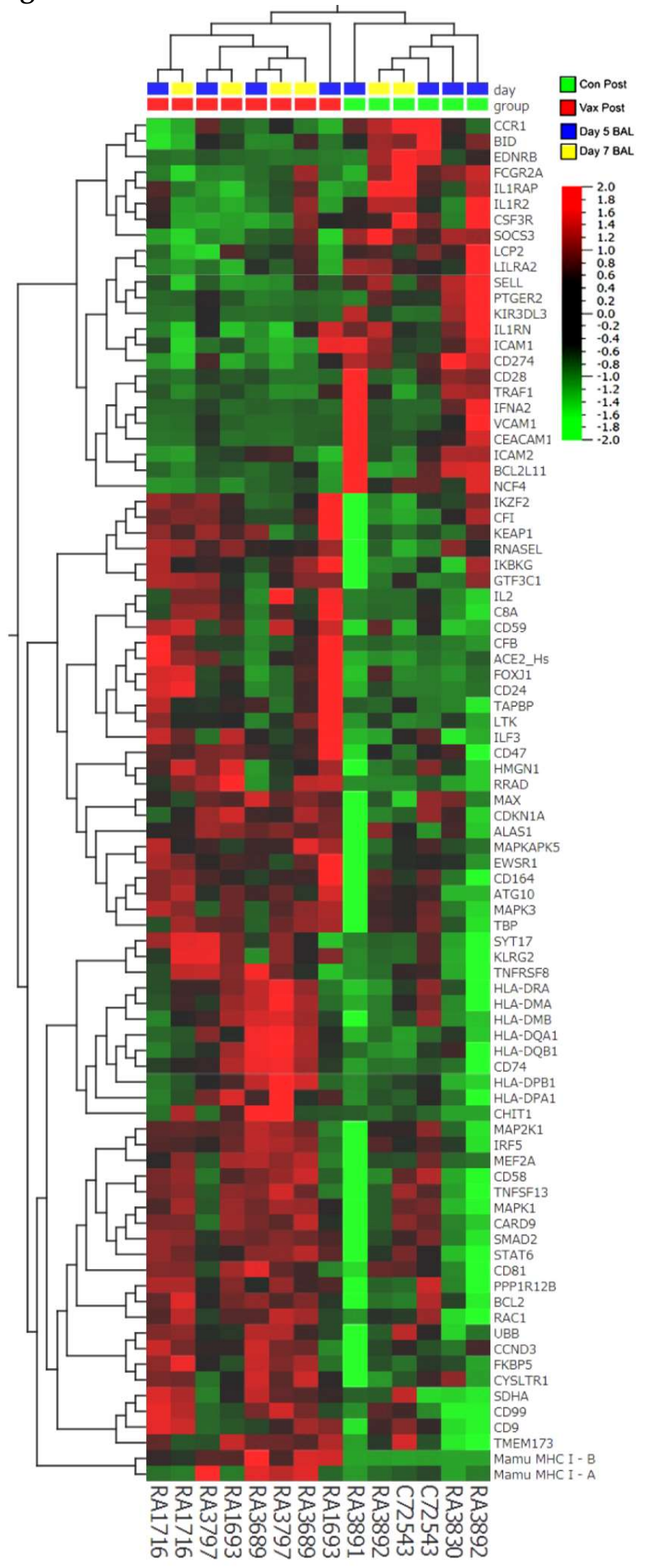

Figure 5 legend. Hierarchical clustering of gene expression in BAL samples collected from control and vaccinated macaques 5and 7- days post SARS-CoV-2 challenge. Heatmap shows significantly $(\mathrm{p}<0.05)$ upregulated (red) genes (63 genes $>3$-fold) and down-regulated (green) genes ( 24 genes $<1 / 3$ fold) from a total of 730 genes analyzed using the NanoString Non-Human Primate Immunology V2 Panel and identifies a set of genes possibly associated with protection from SARS CoV-2 challenge. 


\section{Figure 6}
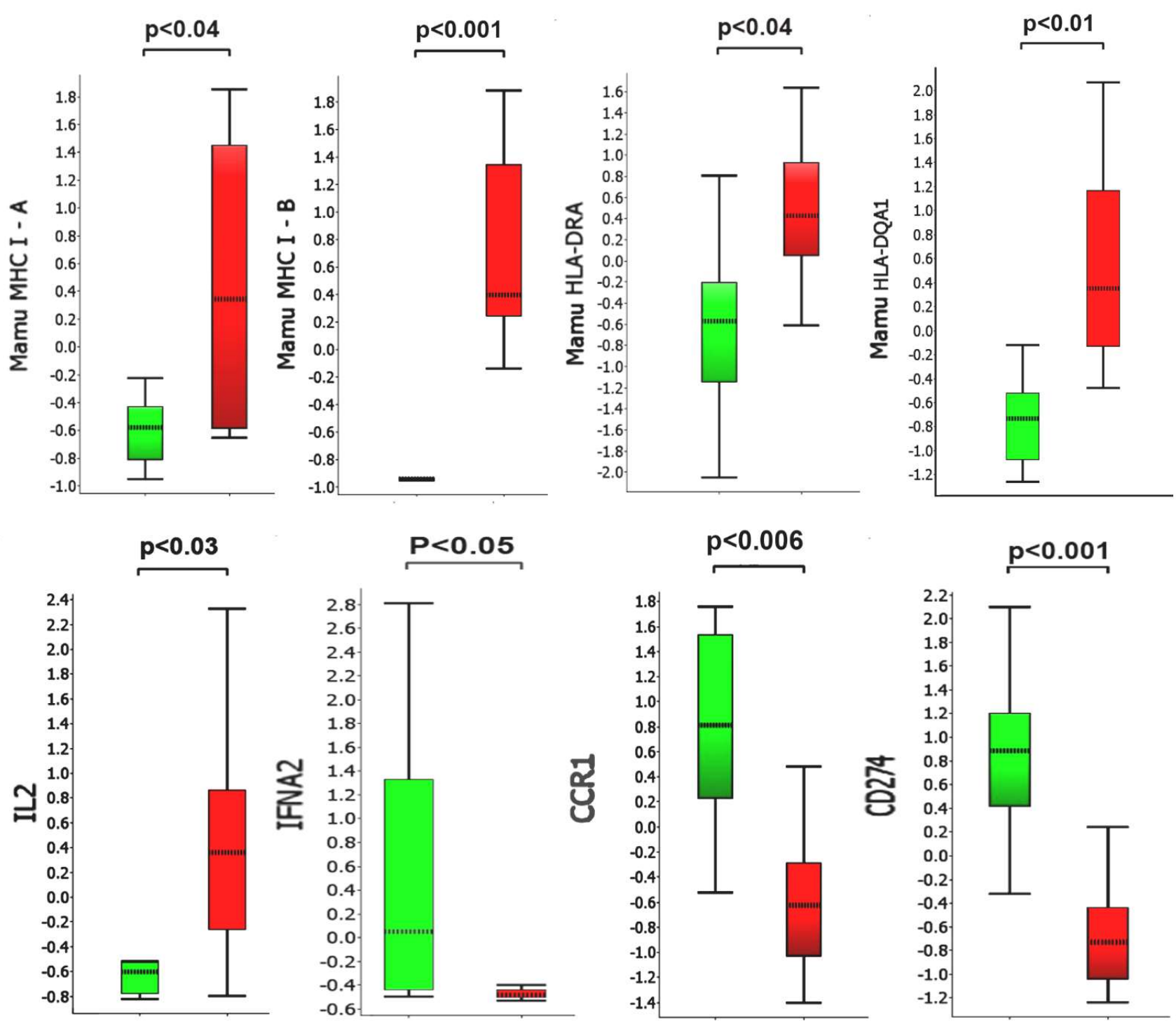

\section{Figure 6 Legend. Comparison of selected transcripts up- or down-regulated in collected BAL} samples 5-7 days post-challenge. Y-axis values represent fold differences in average scaled counts. Green bars and red bars represent control and vaccinated macaques, respectively. P-values below 0.05 were considered significant. 


\begin{tabular}{|c|c|c|c|c|c|}
\hline \multicolumn{6}{|c|}{ Up-regulated Transcripts on Days 5 and 7 Post-Challenge ${ }^{1}$} \\
\hline Gene ID & Function & Distribution & Gene ID & Function & Distribution \\
\hline Mamu MHC1 A & $\begin{array}{l}\text { Antigen presentation to CD8+ } \\
\mathrm{T} \text { cells }{ }^{1}\end{array}$ & $\begin{array}{l}\text { Low cell type } \\
\text { specificity }^{1}\end{array}$ & CD8 & $\begin{array}{l}\text { Co-receptor for TCR binding } \\
\text { to } \mathrm{MHC} \mathrm{C1}\end{array}$ & $\mathrm{T}$ cells \\
\hline Mamu MHC1 B & $\begin{array}{l}\text { Antigen presentation to CD8+ } \\
\mathrm{T} \text { cells }\end{array}$ & $\begin{array}{l}\text { Low cell type } \\
\text { specificity }\end{array}$ & IL2 & $\begin{array}{l}\text { Differentiation/maturation of } \\
\text { T-cells }\end{array}$ & $\begin{array}{l}\text { CD4+ and } \\
\text { CD8+ T cells }\end{array}$ \\
\hline TAPBP & $\begin{array}{l}\text { MHC Class I Antigen presen- } \\
\text { tation }\end{array}$ & $\begin{array}{l}\text { Low cell type } \\
\text { specificity }\end{array}$ & CD81 & $\begin{array}{l}\text { Costimulatory signal with } \\
\text { CD3 }\end{array}$ & $\begin{array}{l}\text { Low cell type } \\
\text { specificity }\end{array}$ \\
\hline HLA-DRA $^{2}$ & $\begin{array}{l}\text { Antigen presentation to CD4+ } \\
\mathrm{T} \text { cells }\end{array}$ & $\begin{array}{l}\text { Professional } \\
\text { APC }\end{array}$ & CD9 & $\begin{array}{l}\text { Cell adhesion, recognized by } \\
\text { CD81 }\end{array}$ & $\begin{array}{l}\text { Low cell type } \\
\text { specificity }\end{array}$ \\
\hline HLA-DQA $1^{2}$ & $\begin{array}{l}\text { Antigen presentation to CD4+ } \\
\mathrm{T} \text { cells }\end{array}$ & $\begin{array}{l}\text { Professional } \\
\text { APC }\end{array}$ & CD59 & $\begin{array}{l}\text { Inhibitor of the complement } \\
\text { membrane attack complex }\end{array}$ & $\begin{array}{l}\text { Low cell type } \\
\text { specificity }\end{array}$ \\
\hline HLA-DQB1 ${ }^{2}$ & $\begin{array}{l}\text { Antigen presentation to CD } 4+ \\
\mathrm{T} \text { cells }\end{array}$ & $\begin{array}{l}\text { Professional } \\
\text { APC }\end{array}$ & $\mathrm{CD} 24$ & Cell adhesion molecule & $\begin{array}{l}\text { Eosinophils } \\
\text { and B cells }\end{array}$ \\
\hline CD74 & $\begin{array}{l}\text { MHC Class II Antigen } \\
\text { presentation }\end{array}$ & $\begin{array}{l}\text { Professional } \\
\text { APC }\end{array}$ & CD47 & $\begin{array}{l}\text { High affinity receptor for } \\
\text { thrombospondin-1 }\end{array}$ & $\begin{array}{l}\text { Low cell type } \\
\text { specificity }\end{array}$ \\
\hline HLA-DMA & $\begin{array}{l}\text { MHC Class II Antigen } \\
\text { presentation }\end{array}$ & $\begin{array}{l}\text { Professional } \\
\text { APC }\end{array}$ & CD58 & $\begin{array}{l}\text { Ligand of the T-lymphocyte } \\
\text { CD2 glycoprotein }\end{array}$ & $\begin{array}{l}\text { Low cell type } \\
\text { specificity }\end{array}$ \\
\hline HLA-DMB & $\begin{array}{l}\text { MHC Class II Antigen } \\
\text { presentation }\end{array}$ & $\begin{array}{l}\text { Professional } \\
\text { APC }\end{array}$ & CD164 & $\begin{array}{l}\text { Facilitates adhesion of CD34+ } \\
\text { cells }\end{array}$ & $\begin{array}{l}\text { Low cell type } \\
\text { specificity }\end{array}$ \\
\hline \multicolumn{3}{|c|}{ Up-regulated Transcripts on Day 5 or 7 Post-Challenge } & \multicolumn{3}{|c|}{ Up-regulated Transcripts on Day 10 Post-Challenge } \\
\hline IL17 B & Proinflamatory cytokine & $\begin{array}{l}\text { Low cell type } \\
\text { specificity }\end{array}$ & IL6R & $\begin{array}{l}\text { Low affinity receptor for Inter- } \\
\text { leukin } 6 .\end{array}$ & Neutrophil \\
\hline CX3CL1 & $\begin{array}{l}\text { Chemotactic for } \mathrm{T} \text { cells and } \\
\text { monocytes }\end{array}$ & $\begin{array}{l}\text { Low cell type } \\
\text { specificity }\end{array}$ & ABL1 & $\begin{array}{l}\text { Tyrosine-protein kinase, role } \\
\text { cell growth and survival }\end{array}$ & $\begin{array}{l}\text { Low cell type } \\
\text { specificity }\end{array}$ \\
\hline CD99 & Facilitates T cell adhesion & $\begin{array}{l}\text { Low cell type } \\
\text { specificity }\end{array}$ & TYK2 & $\begin{array}{l}\text { Tyrosine-protein kinase Initia- } \\
\text { tion of type I IFN signaling }\end{array}$ & $\begin{array}{l}\text { Low cell type } \\
\text { specificity }\end{array}$ \\
\hline
\end{tabular}

${ }^{1}$ Gene annotations supplied by the human protein atlas $[55,56]$

Table 1 - Differentially regulated genes in BAL cells obtained from SARS-CoV-2 challenged vaccinated versus control macaques

\footnotetext{
${ }^{2}$ Macaque equivalent of human HLA Class II
} 
Table 2 - Differentially regulated genes in BAL cells obtained from SARS-CoV-2 challenged vaccinated versus control macaques

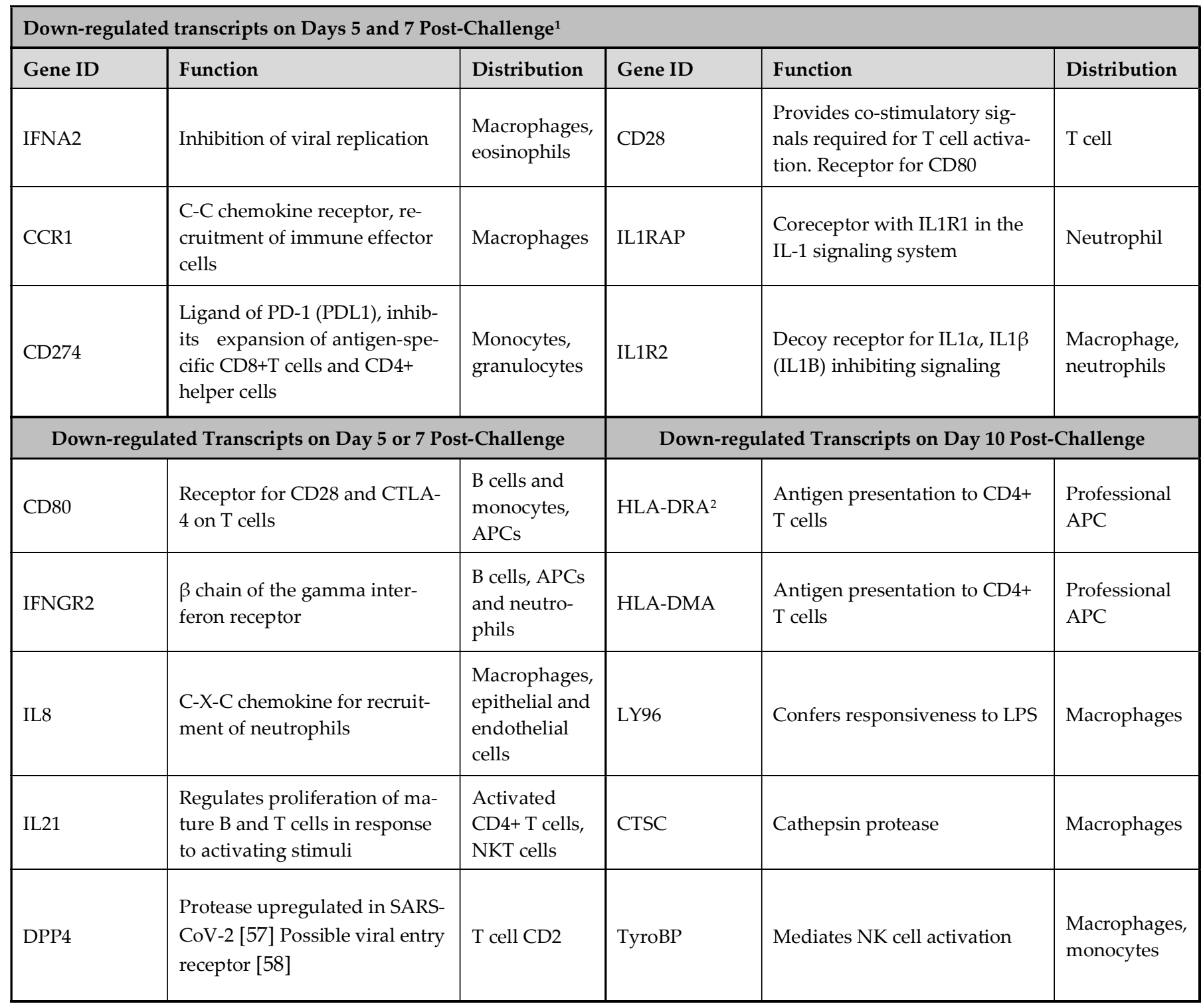

${ }^{1}$ Gene annotations supplied by the human protein atlas $[55,56]$

${ }^{2}$ Macaque equivalent of human HLA Class II 
A major difference between pre-challenge BAL samples was that vaccinated macaques had received prior intratracheal instillation of vaccine formulation containing CpG and MPLA adjuvants. To assess the possible effects and efficacy of our vaccination procedure and formulation, we compared the expression of 60 genes previously reported to be up-regulated, not by antigenic stimulation, but by adjuvants alone [59-63]. We found 30 out of 60 genes examined to be significantly $(\mathrm{p}<0.05)$ and differentially ( $>2$ fold) regulated in BAL cells obtained from vaccinated but unchallenged macaques (Day -7) relative to samples from unchallenged control animals (Day-1) (Supplemental data, Figure S13). This pattern suggests that BAL-associated cells from vaccinated animals were stimulated by the adjuvants in the vaccine formulation. As a further measure of vaccination efficiency, we measured BAL immunoreactivity to the peptides via ELISPOT prior to SARS-CoV-2 challenge (Supplemental data, Figure S14). We observed modest immunoreactivity to one of the six CTL peptides (LL9) in 3 out of the 4 vaccinated pre-challenge macaques. We did not detect immunoreactivity to the peptide antigens using samples of peripheral blood mononuclear cells (data not shown).

\section{Discussion}

In our study, SARS-CoV-2 infection in unvaccinated control macaques progressed similar to previous reports using this model. The post-viral challenge period was clinically characterized by 1) two waves of infectious viral particle recovery in the nasal tissues, 2) lymphopenia on day 1 post-challenge in all animals, and 3) progressive development of pneumonia-like infiltrations visible on chest x-rays as "ground-glass like consolidations", but few changes associate with human SARS COV-2 infection such as loss of appetite, respiratory distress, vomiting and/or diarrhea. We observed that the kinetics of change in viral loads observed in control rhesus macaques were similar to those previously reported [11]. Additionally, the lung tissue abnormalities revealed by chest radiography were similar in the kinetics of progression and depth to previous reports $[6,15,16,20,45-48]$. Together, these observations suggest that SARS CoV-2 infection in the Rhesus model is clinically mild, a conclusion confirming some [6,8,11], but not all [64] previous reports. SARS-CoV-2 infection in microsphere/adjuvant vaccinated macaques progressed in a pattern different from the unvaccinated controls. Specifically, disease was characterized by a trend toward diminished recovery of infectious viral particles from nasal tissues; enhance recovery of peripheral blood lymphocytes counts, and a significant absence of pneumonia-like infiltrates in the lung. Together, these observations suggest that vaccination conferred some degree of protection against SARS CoV-2 induced disease.

Supporting this clinical conclusion were our studies of the gene expression profiles in serially harvested BAL cells from SARS CoV-2 challenged macaques and immunoreactivity of the BAL cells. In samples collected from vaccinated (but pre-viral challenge) macaque BAL cells, we found distinct changes in gene expression associated with the use of TLR 4 and 9 agonists, including up-regulation of CSF1 [61], IRF7 [62], and IL10[60] suggesting effective delivery of the adjuvant portion of the vaccine formulation. When we examined HLA Class I restricted immunoreactivity of the pre-challenge but vaccinated macaque BAL cells towards the vaccinating peptides, we found modest to low reactivity towards one of the peptides (LLLDRLNQL) in three of four NHP subjects vaccinated. 
Following vaccination and viral challenge, we found evidence of up-regulation of both Mamu MHC Class I and Class II genes in macaque BAL cells relative to unvaccinated, viral challenged macaques. Upregulation of HLA Class I and Class II molecules in peripheral blood mononuclear cells has been reported following the measles /mumps/rubella (MMR) vaccine in MMR naïve individuals [65]. Increased signatures of M1-type macrophage APC transcripts in the BAL of SARS-CoV-2 infected rhesus macaques has been previously reported [5]; however our finding of upregulated expression of MHC Class II genes, a hallmark of professional APCs, appears to be unique to the BAL of our vaccinated macaques. Likewise, we found increased up-regulation of the IL2 genes in vaccinated relative to unvaccinated macaques. A similar finding has been reported in humans where higher IL 2 levels distinguish mild/asymptomatic forms of COVID-19 disease from the moderate/severe forms [66]. Following viral challenge in our study (specifically, Day 5 to 7), we found down-regulation of IFN $\alpha 2$ genes in BAL cells recovered from vaccinated subjects relative to their unvaccinated controls. The observation perhaps reflects the decreased viral loads found in vaccinated NHP subjects [5].

While antibodies are a critical component of the protective humoral immune response to pathogens, antibodies that promote disease have been described and categorized as ADE [67] or VAERD, such as that described in MERS-CoV or RSV patients [68-70]. Since our vaccine only delivered low molecular weight nonameric synthetic peptides, unconjugated to any carrier, we did not expect to generate a significant anti-peptide humoral response. Rather, during the development and testing of the microsphere synthetic peptide COVID 19 vaccine, we were mindful of evoking Th2 biased immune responses, particularly those that occur in the absence of Th1 responses or appropriate $\mathrm{T}$ regulatory cell responses [71]. The gene expression patterns of BAL cells obtained from the vaccinated macaques in our study suggested that we did not provoke an unbalanced Th2 response by vaccination.

We note several weaknesses in our approach to demonstrate the efficacy of this experimental vaccine: 1) SARS-CoV-2 infection in Rhesus macaques resulted in only mild disease, which appears to resolve by day 10-14 post-infection. Having noted this in previous reports on the SARS-CoV-2 /rhesus model, we tried to induce more severe forms of infection using higher doses of infectious particles than previous reports. Based on clinical signs, we found little effect of the increased dose of the virus on Rhesus SARS-CoV-2 disease severity. 2) Because of the limited amount of cells recovered from the BAL, we were where unable to perform confirmatory quantitative RT-PCR analysis of the unique gene expression patterns found in vaccinated versus control BAL. Nevertheless, we found that many of our observations have been previously reported from studies in similar models, 3) Not all the macaque chest radiographs were performed on the same day in control versus vaccinated subjects, a reflection of the logistic difficulties in working under BSL $3 / 4$ conditions. We are confident, however, we have captured the chest radiographic abnormalities induced by SAR-CoV-2 infection of macaques (i.e. conspicuous consolidations and infiltrations prevalent in the caudal lobe of the right lung), and adequately shown their absence in vaccinated viral challenged macaques, 4) we only included one cynomolgus macaque in our control group. This was primarily due to macaque availability at the time the study was conducted. However, this appears to have been both a strength [64] and weakness of the experimental design, as we found similar lung pathology in the cynomolgus macaque as well as similar patterns of BAL gene expression as the controls Rhesus subjects [72], 
and 5) we did not study the effects of adjuvant alone on SARS-Cov-2 infection in the Rhesus macaques. Previous experience with this microsphere CTL vaccine platform in a murine Ebola virus model has shown that adjuvant alone was not sufficient to confer protection against lethal virus challenge. Protection was conferred only when the corresponding synthetic CTL peptide epitopes were delivered in the microsphere [4].

We believe this report is the first demonstration of efficacy in a preclinical NHP model of SARS CoV-2 infection of a synthetic peptide-based vaccine based on known and persistently immunogenic HLA Class I bound CTL peptide epitopes of SARS nucleoprotein [28]. The SARS-CoV-2 nucleoprotein genomic sequences have shown significantly reduced mutations rates compared to spike protein. As such, it may represent an additional target for vaccination, perhaps in the context of a booster vaccine used following SARS-CoV-2 spike protein vaccines based on recombinant protein, mRNA, or adenoviral vectors [73-75]. The ready ability to change the sequence of the synthetic peptide HLA Class I restricted CTL epitopes used in the system is an attractive feature, given the observed rates of mutation in SARS-CoV-2 as it spreads in the human population in the future. A second potentially attractive feature of this vaccine approach is that it can be delivered by aerosolization to the respiratory mucosa, a route previously demonstrated to generate efficiently lungdwelling tissue-resident memory T cells [76,77].

\section{Conclusions}

We demonstrate that Rhesus macaques receiving the microsphere vaccine formulation prior to viral challenge are protected from pneumonia-like lung abnormalities that characterize SARS CoV-2 infection in unvaccinated control macaques. Analysis of gene expression of cells obtained from bronchiolar lavage shows unique signatures consistent with the hypothesis that vaccination with this platform induces a protective $\mathrm{T}$ cell response in viral challenged macaques.

\section{Conflict of Interest / Competing Interests Disclosures and Contributions}

R.R., T.Bl., S.B., S.C., R.C., T.H., L.W., P.L., and C.H. are employees of Flow Pharma, Inc. compensated in cash and stock, and are named inventors on various issued and pending patents assigned to Flow Pharma. Some of these patents pending are directly related to the study presented here. P.H. is a member of Flow Pharma's Scientific Advisory Board. T.Be. is a Flow Pharma stockholder. The remaining authors declare that the research was conducted in the absence of any commercial or financial relationships that could be construed as a potential conflict of interest. All authors made substantial contributions to: (1) the conception and design of the study (R.R., S.B., S.C.,T.Br., J.C., P.H., C.H., T.Be.), or acquisition of data (T.Br. C.M. J.C., C.H.), or analysis and interpretation of data (R.R., P.H., T.Br., J.C.), (2) drafting the article or revising it critically for important intellectual content (P.H., T.Br. S.B., T.H., T.Bl., P.L., R.R.) (3) and all authors have approved the final version of the submitted manuscript.

\section{Acknowledgments}

The authors wish to thank Dr. Antonella Maffei for her critical review of the manuscript. 


\section{Funding Sources}

This research did not receive any specific external grant from funding agencies in the public, commercial, or not-for-profit sectors.

\section{Data Availability Statement:}

The original DICOM files (> $20 \mathrm{MB} /$ file) are available upon request.

\section{Appendix: none}

\section{References}

1. Hannah Ritchie, E.O.-O., Diana Beltekian, Edouard Mathieu, Joe Hasell, Bobbie Macdonald, Charlie Giattino, and Max Roser. Coronavirus (COVID-19) Vaccinations. Availabe online: https://ourworldindata.org/covid-vaccinations (accessed on 1/31/2021).

2. Hoffmann, M.; Arora, P.; Gross, R.; Seidel, A.; Hornich, B.F.; Hahn, A.S.; Kruger, N.; Graichen, L.; Hofmann-Winkler, H.; Kempf, A., et al. SARS-CoV-2 variants B.1.351 and P.1 escape from neutralizing antibodies. Cell 2021, 10.1016/j.cell.2021.03.036, doi:10.1016/j.cell.2021.03.036.

3. Rubsamen, R.M.; Herst, C.V.; Lloyd, P.M.; Heckerman, D.E. Eliciting cytotoxic T-lymphocyte responses from synthetic vectors containing one or two epitopes in a C57BL/6 mouse model using peptide-containing biodegradable microspheres and adjuvants. Vaccine 2014, 32, 41114116, doi:10.1016/j.vaccine.2014.05.071.

4. Herst, C.V.; Burkholz, S.; Sidney, J.; Sette, A.; Harris, P.E.; Massey, S.; Brasel, T.; Cunha-Neto, E.; Rosa, D.S.; Chao, W.C.H., et al. An effective CTL peptide vaccine for Ebola Zaire Based on Survivors' CD8+ targeting of a particular nucleocapsid protein epitope with potential implications for COVID-19 vaccine design. Vaccine 2020, 38, 4464-4475, doi:10.1016/j.vaccine.2020.04.034.

5. Aid, M.; Busman-Sahay, K.; Vidal, S.J.; Maliga, Z.; Bondoc, S.; Starke, C.; Terry, M.; Jacobson, C.A.; Wrijil, L.; Ducat, S., et al. Vascular Disease and Thrombosis in SARS-CoV-2-Infected Rhesus Macaques. Cell 2020, 183, 1354-1366 e1313, doi:10.1016/j.cell.2020.10.005.

6. Blair, R.V.; Vaccari, M.; Doyle-Meyers, L.A.; Roy, C.J.; Russell-Lodrigue, K.; Fahlberg, M.; Monjure, C.J.; Beddingfield, B.; Plante, K.S.; Plante, J.A., et al. Acute Respiratory Distress in Aged, SARS-CoV-2-Infected African Green Monkeys but Not Rhesus Macaques. Am J Pathol 2020, 10.1016/j.ajpath.2020.10.016, doi:10.1016/j.ajpath.2020.10.016.

7. Bray, M.; Hatfill, S.; Hensley, L.; Huggins, J.W. Haematological, biochemical and coagulation changes in mice, guinea-pigs and monkeys infected with a mouse-adapted variant of Ebola Zaire virus. J Comp Pathol 2001, 125, 243-253, doi:10.1053/jcpa.2001.0503.

8. Chandrashekar, A.; Liu, J.; Martinot, A.J.; McMahan, K.; Mercado, N.B.; Peter, L.; Tostanoski, L.H.; Yu, J.; Maliga, Z.; Nekorchuk, M., et al. SARS-CoV-2 infection protects against rechallenge in rhesus macaques. Science 2020, 369, 812-817, doi:10.1126/science.abc4776. 
9. Deng, W.; Bao, L.; Liu, J.; Xiao, C.; Liu, J.; Xue, J.; Lv, Q.; Qi, F.; Gao, H.; Yu, P., et al. Primary exposure to SARS-CoV-2 protects against reinfection in rhesus macaques. Science 2020, 369, 818-823, doi:10.1126/science.abc5343.

10. Feng, L.; Wang, Q.; Shan, C.; Yang, C.; Feng, Y.; Wu, J.; Liu, X.; Zhou, Y.; Jiang, R.; Hu, P., et al. An adenovirus-vectored COVID-19 vaccine confers protection from SARS-COV-2 challenge in rhesus macaques. Nat Commun 2020, 11, 4207, doi:10.1038/s41467-020-18077-5.

11. McAuliffe, J.; Vogel, L.; Roberts, A.; Fahle, G.; Fischer, S.; Shieh, W.J.; Butler, E.; Zaki, S.; St Claire, M.; Murphy, B., et al. Replication of SARS coronavirus administered into the respiratory tract of African Green, rhesus and cynomolgus monkeys. Virology 2004, 330, 8-15, doi:10.1016/j.virol.2004.09.030.

12. McMahan, K.; Yu, J.; Mercado, N.B.; Loos, C.; Tostanoski, L.H.; Chandrashekar, A.; Liu, J.; Peter, L.; Atyeo, C.; Zhu, A., et al. Correlates of protection against SARS-CoV-2 in rhesus macaques. Nature 2020, 10.1038/s41586-020-03041-6, doi:10.1038/s41586-020-03041-6.

13. Mercado, N.B.; Zahn, R.; Wegmann, F.; Loos, C.; Chandrashekar, A.; Yu, J.; Liu, J.; Peter, L.; McMahan, K.; Tostanoski, L.H., et al. Single-shot Ad26 vaccine protects against SARS-CoV2 in rhesus macaques. Nature 2020, 586, 583-588, doi:10.1038/s41586-020-2607-z.

14. Mukhopadhyay, L.; Yadav, P.D.; Gupta, N.; Mohandas, S.; Patil, D.Y.; Shete-Aich, A.; Panda, S.; Bhargava, B. Comparison of the immunogenicity \& protective efficacy of various SARSCoV-2 vaccine candidates in non-human primates. Indian $J$ Med Res 2020, 10.4103/ijmr.IJMR_4431_20, doi:10.4103/ijmr.IJMR_4431_20.

15. Munster, V.J.; Feldmann, F.; Williamson, B.N.; van Doremalen, N.; Perez-Perez, L.; Schulz, J.; Meade-White, K.; Okumura, A.; Callison, J.; Brumbaugh, B., et al. Respiratory disease and virus shedding in rhesus macaques inoculated with SARS-CoV-2. bioRxiv 2020, 10.1101/2020.03.21.001628, doi:10.1101/2020.03.21.001628.

16. Shan, C.; Yao, Y.F.; Yang, X.L.; Zhou, Y.W.; Gao, G.; Peng, Y.; Yang, L.; Hu, X.; Xiong, J.; Jiang, R.D., et al. Infection with novel coronavirus (SARS-CoV-2) causes pneumonia in Rhesus macaques. Cell Res 2020, 30, 670-677, doi:10.1038/s41422-020-0364-z.

17. Singh, D.K.; Singh, B.; Ganatra, S.R.; Gazi, M.; Cole, J.; Thippeshappa, R.; Alfson, K.J.; Clemmons, E.; Gonzalez, O.; Escobedo, R., et al. Responses to acute infection with SARSCoV-2 in the lungs of rhesus macaques, baboons and marmosets. Nat Microbiol 2021, 6, 73-86, doi:10.1038/s41564-020-00841-4.

18. Song, T.Z.; Zheng, H.Y.; Han, J.B.; Jin, L.; Yang, X.; Liu, F.L.; Luo, R.H.; Tian, R.R.; Cai, H.R.; Feng, X.L., et al. Delayed severe cytokine storm and immune cell infiltration in SARS-CoV2-infected aged Chinese rhesus macaques. Zool Res 2020, 41, 503-516, doi:10.24272/j.issn.20958137.2020.202.

19. van Doremalen, N.; Lambe, T.; Spencer, A.; Belij-Rammerstorfer, S.; Purushotham, J.N.; Port, J.R.; Avanzato, V.; Bushmaker, T.; Flaxman, A.; Ulaszewska, M., et al. ChAdOx1 nCoV-19 vaccination prevents SARS-CoV-2 pneumonia in rhesus macaques. bioRxiv 2020, 10.1101/2020.05.13.093195, doi:10.1101/2020.05.13.093195.

20. Yu, P.; Qi, F.; Xu, Y.; Li, F.; Liu, P.; Liu, J.; Bao, L.; Deng, W.; Gao, H.; Xiang, Z., et al. Agerelated rhesus macaque models of COVID-19. Animal Model Exp Med 2020, 3, 93-97, doi:10.1002/ame2.12108. 
21. Zheng, H.; Li, H.; Guo, L.; Liang, Y.; Li, J.; Wang, X.; Hu, Y.; Wang, L.; Liao, Y.; Yang, F., et al. Virulence and pathogenesis of SARS-CoV-2 infection in rhesus macaques: A nonhuman primate model of COVID-19 progression. PLoS Pathog 2020, 16, e1008949, doi:10.1371/journal.ppat.1008949.

22. Corbett, K.S.; Flynn, B.; Foulds, K.E.; Francica, J.R.; Boyoglu-Barnum, S.; Werner, A.P.; Flach, B.; O'Connell, S.; Bock, K.W.; Minai, M., et al. Evaluation of the mRNA-1273 Vaccine against SARS-CoV-2 in Nonhuman Primates. $N$ Engl J Med 2020, 383, 1544-1555, doi:10.1056/NEJMoa2024671.

23. Gao, Q.; Bao, L.; Mao, H.; Wang, L.; Xu, K.; Yang, M.; Li, Y.; Zhu, L.; Wang, N.; Lv, Z., et al. Development of an inactivated vaccine candidate for SARS-CoV-2. Science 2020, 369, 77-81, doi:10.1126/science.abc1932.

24. Guebre-Xabier, M.; Patel, N.; Tian, J.H.; Zhou, B.; Maciejewski, S.; Lam, K.; Portnoff, A.D.; Massare, M.J.; Frieman, M.B.; Piedra, P.A., et al. NVX-CoV2373 vaccine protects cynomolgus macaque upper and lower airways against SARS-CoV-2 challenge. Vaccine 2020, 38, 78927896, doi:10.1016/j.vaccine.2020.10.064.

25. Zhang, N.N.; Li, X.F.; Deng, Y.Q.; Zhao, H.; Huang, Y.J.; Yang, G.; Huang, W.J.; Gao, P.; Zhou, C.; Zhang, R.R., et al. A Thermostable mRNA Vaccine against COVID-19. Cell 2020, 182, 12711283 e1216, doi:10.1016/j.cell.2020.07.024.

26. Wang, H.; Zhang, Y.; Huang, B.; Deng, W.; Quan, Y.; Wang, W.; Xu, W.; Zhao, Y.; Li, N.; Zhang, J., et al. Development of an Inactivated Vaccine Candidate, BBIBP-CorV, with Potent Protection against SARS-CoV-2. Cell 2020, 182, 713-721 e719, doi:10.1016/j.cell.2020.06.008.

27. Yu, J.; Tostanoski, L.H.; Peter, L.; Mercado, N.B.; McMahan, K.; Mahrokhian, S.H.; Nkolola, J.P.; Liu, J.; Li, Z.; Chandrashekar, A., et al. DNA vaccine protection against SARS-CoV-2 in rhesus macaques. Science 2020, 369, 806-811, doi:10.1126/science.abc6284.

28. Peng, H.; Yang, L.T.; Wang, L.Y.; Li, J.; Huang, J.; Lu, Z.Q.; Koup, R.A.; Bailer, R.T.; Wu, C.Y. Long-lived memory $\mathrm{T}$ lymphocyte responses against SARS coronavirus nucleocapsid protein in SARS-recovered patients. Virology 2006, 351, 466-475, doi:10.1016/j.virol.2006.03.036.

29. Peng, Y.; Mentzer, A.J.; Liu, G.; Yao, X.; Yin, Z.; Dong, D.; Dejnirattisai, W.; Rostron, T.; Supasa, P.; Liu, C., et al. Broad and strong memory CD4(+) and CD8(+) T cells induced by SARS-CoV-2 in UK convalescent individuals following COVID-19. Nat Immunol 2020, 21, 1336-1345, doi:10.1038/s41590-020-0782-6.

30. Kared, H.; Redd, A.D.; Bloch, E.M.; Bonny, T.S.; Sumatoh, H.R.; Kairi, F.; Carbajo, D.; Abel, B.; Newell, E.W.; Bettinotti, M., et al. SARS-CoV-2-specific CD8+ T cell responses in convalescent COVID-19 individuals. J Clin Invest 2021, 10.1172/JCI145476, doi:10.1172/JCI145476.

31. Grifoni, A.; Weiskopf, D.; Ramirez, S.I.; Mateus, J.; Dan, J.M.; Moderbacher, C.R.; Rawlings, S.A.; Sutherland, A.; Premkumar, L.; Jadi, R.S., et al. Targets of T Cell Responses to SARSCoV-2 Coronavirus in Humans with COVID-19 Disease and Unexposed Individuals. Cell 2020, 181, 1489-1501 e1415, doi:10.1016/j.cell.2020.05.015.

32. Ravi, R.K.; Walton, K.; Khosroheidari, M. MiSeq: A Next Generation Sequencing Platform for Genomic Analysis. Methods Mol Biol 2018, 1706, 223-232, doi:10.1007/978-1-4939-7471-9_12.

33. Grifoni, A.; Sidney, J.; Zhang, Y.; Scheuermann, R.H.; Peters, B.; Sette, A. A Sequence Homology and Bioinformatic Approach Can Predict Candidate Targets for Immune 
Responses to SARS-CoV-2. Cell Host Microbe 2020, 27, 671-680 e672, doi:10.1016/j.chom.2020.03.002.

34. Dimonte, S.; Babakir-Mina, M.; Hama-Soor, T.; Ali, S. Genetic Variation and Evolution of the 2019 Novel Coronavirus. Public Health Genomics 2021, 10.1159/000513530, 1-13, doi:10.1159/000513530.

35. Almazan, F.; Galan, C.; Enjuanes, L. The nucleoprotein is required for efficient coronavirus genome replication. J Virol 2004, 78, 12683-12688, doi:10.1128/JVI.78.22.12683-12688.2004.

36. Vita, R.; Mahajan, S.; Overton, J.A.; Dhanda, S.K.; Martini, S.; Cantrell, J.R.; Wheeler, D.K.; Sette, A.; Peters, B. The Immune Epitope Database (IEDB): 2018 update. Nucleic Acids Res 2019, 47, D339-D343, doi:10.1093/nar/gky1006.

37. Jurtz, V.; Paul, S.; Andreatta, M.; Marcatili, P.; Peters, B.; Nielsen, M. NetMHCpan-4.0: Improved Peptide-MHC Class I Interaction Predictions Integrating Eluted Ligand and Peptide Binding Affinity Data. J Immunol 2017, 199, 3360-3368, doi:10.4049/jimmunol.1700893.

38. Qin, E.; Zhu, Q.; Yu, M.; Fan, B.; Chang, G.; Si, B.; Yang, B.; Peng, W.; Jiang, T.; Liu, B., et al. A complete sequence and comparative analysis of a SARS-associated virus (Isolate BJ01). Chin Sci Bull 2003, 48, 941-948, doi:10.1007/BF03184203.

39. Poran, A.; Harjanto, D.; Malloy, M.; Arieta, C.M.; Rothenberg, D.A.; Lenkala, D.; van Buuren, M.M.; Addona, T.A.; Rooney, M.S.; Srinivasan, L., et al. Sequence-based prediction of SARS$\mathrm{CoV}-2$ vaccine targets using a mass spectrometry-based bioinformatics predictor identifies immunogenic T cell epitopes. Genome Med 2020, 12, 70, doi:10.1186/s13073-020-00767-w.

40. Mothe, B.R.; Southwood, S.; Sidney, J.; English, A.M.; Wriston, A.; Hoof, I.; Shabanowitz, J.; Hunt, D.F.; Sette, A. Peptide-binding motifs associated with MHC molecules common in Chinese rhesus macaques are analogous to those of human HLA supertypes and include HLA-B27-like alleles. Immunogenetics 2013, 65, 371-386, doi:10.1007/s00251-013-0686-9.

41. Cunha-Neto, E.; Rosa, D.S.; Harris, P.E.; Olson, T.; Morrow, A.; Ciotlos, S.; Herst, C.V.; Rubsamen, R.M. An Approach for a Synthetic CTL Vaccine Design against Zika Flavivirus Using Class I and Class II Epitopes Identified by Computer Modeling. Front Immunol 2017, 8, 640, doi:10.3389/fimmu.2017.00640.

42. Brining, D.L.; Mattoon, J.S.; Kercher, L.; LaCasse, R.A.; Safronetz, D.; Feldmann, H.; Parnell, M.J. Thoracic radiography as a refinement methodology for the study of H1N1 influenza in cynomologus macaques (Macaca fascicularis). Comp Med 2010, 60, 389-395.

43. Ramakrishnan, M.A. Determination of $50 \%$ endpoint titer using a simple formula. World J Virol 2016, 5, 85-86, doi:10.5501/wjv.v5.i2.85.

44. Hochberg, Y.; Benjamini, Y. More powerful procedures for multiple significance testing. Stat Med 1990, 9, 811-818, doi:10.1002/sim.4780090710.

45. Finch, C.L.; Crozier, I.; Lee, J.H.; Byrum, R.; Cooper, T.K.; Liang, J.; Sharer, K.; Solomon, J.; Sayre, P.J.; Kocher, G., et al. Characteristic and quantifiable COVID-19-like abnormalities in CT- and PET/CT-imaged lungs of SARS-CoV-2-infected crab-eating macaques (Macaca fascicularis). bioRxiv 2020, 10.1101/2020.05.14.096727, doi:10.1101/2020.05.14.096727.

46. Lu, S.; Zhao, Y.; Yu, W.; Yang, Y.; Gao, J.; Wang, J.; Kuang, D.; Yang, M.; Yang, J.; Ma, C., et al. Comparison of nonhuman primates identified the suitable model for COVID-19. Signal Transduct Target Ther 2020, 5, 157, doi:10.1038/s41392-020-00269-6. 
47. Xie, L.; Zhou, Q.; Liu, S.; Wu, Q.; Ji, Y.; Zhang, L.; Xu, F.; Gong, W.; Melgiri, N.D.; Xie, P. Normal thoracic radiographic appearance of the cynomolgus monkey (Macaca fascicularis). PLoS One 2014, 9, e84599, doi:10.1371/journal.pone.0084599.

48. Silverman, S.; Morgan, J.P. Thoracic radiography of the normal rhesus macaque (Macaca mulatta). Am J Vet Res 1980, 41, 1704-1719.

49. Singh, D.K.; Ganatra, S.R.; Singh, B.; Cole, J.; Alfson, K.J.; Clemmons, E.; Gazi, M.; Gonzalez, O.; Escobedo, R.; Lee, T.-H., et al. SARS-CoV-2 infection leads to acute infection with dynamic cellular and inflammatory flux in the lung that varies across nonhuman primate species. bioRxiv 2020, 2020.2006.2005.136481, doi:10.1101/2020.06.05.136481.

50. Annemiek Maaskant, L.M., Jaco Bakker, Leo van Geest, Dian G.M. Zijlmans, Jan A.M. Langermans, Ernst J.Verschoor, Marieke A. Stammes. Bronchoalveolar lavage affects thorax computed tomography of healthy and SARS-CoV-2 infected rhesus macaques (Macaca mulatta) bioRxiv preprint 2021, https://doi.org/10.1101/2021.02.04.429761 doi: https://doi.org/10.1101/2021.02.04.429761

51. Rabenstein, H.; Behrendt, A.C.; Ellwart, J.W.; Naumann, R.; Horsch, M.; Beckers, J.; Obst, R. Differential kinetics of antigen dependency of CD4+ and CD8+ T cells. J Immunol 2014, 192, 3507-3517, doi:10.4049/jimmunol.1302725.

52. Trobaugh, D.W.; Yang, L.; Ennis, F.A.; Green, S. Altered effector functions of virus-specific and virus cross-reactive CD8+ T cells in mice immunized with related flaviviruses. Eur J Immunol 2010, 40, 1315-1327, doi:10.1002/eji.200839108.

53. Lin, L.; Spoor, M.S.; Gerth, A.J.; Brody, S.L.; Peng, S.L. Modulation of Th1 activation and inflammation by the NF-kappaB repressor Foxj1. Science 2004, 303, 1017-1020, doi:10.1126/science.1093889.

54. Fitzpatrick, A.M.; Higgins, M.; Holguin, F.; Brown, L.A.; Teague, W.G.; National Institutes of Health/National Heart, L.; Blood Institute's Severe Asthma Research, P. The molecular phenotype of severe asthma in children. J Allergy Clin Immunol 2010, 125, 851-857 e818, doi:10.1016/j.jaci.2010.01.048.

55. Uhlen, M.; Fagerberg, L.; Hallstrom, B.M.; Lindskog, C.; Oksvold, P.; Mardinoglu, A.; Sivertsson, A.; Kampf, C.; Sjostedt, E.; Asplund, A., et al. Proteomics. Tissue-based map of the human proteome. Science 2015, 347, 1260419, doi:10.1126/science.1260419.

56. Uhlen, M.; Karlsson, M.J.; Zhong, W.; Tebani, A.; Pou, C.; Mikes, J.; Lakshmikanth, T.; Forsstrom, B.; Edfors, F.; Odeberg, J., et al. A genome-wide transcriptomic analysis of proteincoding genes in human blood cells. Science 2019, 366, doi:10.1126/science.aax9198.

57. Amati, F.; Vancheri, C.; Latini, A.; Colona, V.L.; Grelli, S.; D'Apice, M.R.; Balestrieri, E.; Passarelli, C.; Minutolo, A.; Loddo, S., et al. Expression profiles of the SARS-CoV-2 host invasion genes in nasopharyngeal and oropharyngeal swabs of COVID-19 patients. Heliyon 2020, 6, e05143, doi:10.1016/j.heliyon.2020.e05143.

58. Raj, V.S.; Mou, H.; Smits, S.L.; Dekkers, D.H.; Muller, M.A.; Dijkman, R.; Muth, D.; Demmers, J.A.; Zaki, A.; Fouchier, R.A., et al. Dipeptidyl peptidase 4 is a functional receptor for the emerging human coronavirus-EMC. Nature 2013, 495, 251-254, doi:10.1038/nature12005. 
59. Salyer, A.C.D.; David, S.A. Transcriptomal signatures of vaccine adjuvants and accessory immunostimulation of sentinel cells by toll-like receptor 2/6 agonists. Hum Vaccin Immunother 2018, 14, 1686-1696, doi:10.1080/21645515.2018.1480284.

60. Olafsdottir, T.; Lindqvist, M.; Harandi, A.M. Molecular signatures of vaccine adjuvants. Vaccine 2015, 33, 5302-5307, doi:10.1016/j.vaccine.2015.04.099.

61. Mosca, F.; Tritto, E.; Muzzi, A.; Monaci, E.; Bagnoli, F.; Iavarone, C.; O'Hagan, D.; Rappuoli, R.; De Gregorio, E. Molecular and cellular signatures of human vaccine adjuvants. Proc Natl Acad Sci U S A 2008, 105, 10501-10506, doi:10.1073/pnas.0804699105.

62. Lampe, A.T.; Puniya, B.L.; Pannier, A.K.; Helikar, T.; Brown, D.M. Combined TLR4 and TLR9 agonists induce distinct phenotypic changes in innate immunity in vitro and in vivo. Cell Immunol 2020, 355, 104149, doi:10.1016/j.cellimm.2020.104149.

63. An, H.; Xu, H.; Yu, Y.; Zhang, M.; Qi, R.; Yan, X.; Liu, S.; Wang, W.; Guo, Z.; Qin, Z., et al. Up-regulation of TLR9 gene expression by LPS in mouse macrophages via activation of NFkappaB, ERK and p38 MAPK signal pathways. Immunol Lett 2002, 81, 165-169, doi:10.1016/s0165-2478(02)00010-x.

64. Fahlberg, M.D.; Blair, R.V.; Doyle-Meyers, L.A.; Midkiff, C.C.; Zenere, G.; Russell-Lodrigue, K.E.; Monjure, C.J.; Haupt, E.H.; Penney, T.P.; Lehmicke, G., et al. Cellular events of acute, resolving or progressive COVID-19 in SARS-CoV-2 infected non-human primates. Nat Commun 2020, 11, 6078, doi:10.1038/s41467-020-19967-4.

65. Dhiman, N.; Bonilla, R.G.; Jacobson, R.M.; O'Kane, D.; Poland, G.A. Differential HLA gene expression in measles vaccine seropositive and seronegative subjects: a pilot study. Scand J Infect Dis 2003, 35, 332-336, doi:10.1080/00365540310007105.

66. Tjan, L.H.; Furukawa, K.; Nagano, T.; Kiriu, T.; Nishimura, M.; Arii, J.; Hino, Y.; Iwata, S.; Nishimura, Y.; Mori, Y. Early differences in cytokine production distinguish severity of COVID-19. J Infect Dis 2021, 10.1093/infdis/jiab005, doi:10.1093/infdis/jiab005.

67. Katzelnick, L.C.; Gresh, L.; Halloran, M.E.; Mercado, J.C.; Kuan, G.; Gordon, A.; Balmaseda, A.; Harris, E. Antibody-dependent enhancement of severe dengue disease in humans. Science 2017, 358, 929-932, doi:10.1126/science.aan6836.

68. Chin, J.; Magoffin, R.L.; Shearer, L.A.; Schieble, J.H.; Lennette, E.H. Field evaluation of a respiratory syncytial virus vaccine and a trivalent parainfluenza virus vaccine in a pediatric population. Am J Epidemiol 1969, 89, 449-463, doi:10.1093/oxfordjournals.aje.a120957.

69. Kim, H.W.; Canchola, J.G.; Brandt, C.D.; Pyles, G.; Chanock, R.M.; Jensen, K.; Parrott, R.H. Respiratory syncytial virus disease in infants despite prior administration of antigenic inactivated vaccine. Am J Epidemiol 1969, 89, 422-434, doi:10.1093/oxfordjournals.aje.a120955.

70. Rauh, L.W.; Schmidt, R. Measles Immunization with Killed Virus Vaccine. Serum Antibody Titers and Experience with Exposure to Measles Epidemic. Am J Dis Child 1965, 109, 232-237, doi:10.1001/archpedi.1965.02090020234007.

71. Georas, S.N.; Guo, J.; De Fanis, U.; Casolaro, V. T-helper cell type-2 regulation in allergic disease. Eur Respir J 2005, 26, 1119-1137, doi:10.1183/09031936.05.00006005.

72. Salguero, F.J.; White, A.D.; Slack, G.S.; Fotheringham, S.A.; Bewley, K.R.; Gooch, K.E.; Longet, S.; Humphries, H.E.; Watson, R.J.; Hunter, L., et al. Comparison of rhesus and cynomolgus macaques as an infection model for COVID-19. Nat Commun 2021, 12, 1260, doi:10.1038/s41467-021-21389-9. 
73. Logunov, D.Y.; Dolzhikova, I.V.; Zubkova, O.V.; Tukhvatulin, A.I.; Shcheblyakov, D.V.; Dzharullaeva, A.S.; Grousova, D.M.; Erokhova, A.S.; Kovyrshina, A.V.; Botikov, A.G., et al. Safety and immunogenicity of an rAd26 and rAd5 vector-based heterologous prime-boost COVID-19 vaccine in two formulations: two open, non-randomised phase 1/2 studies from Russia. Lancet 2020, 396, 887-897, doi:10.1016/S0140-6736(20)31866-3.

74. Zhu, F.C.; Guan, X.H.; Li, Y.H.; Huang, J.Y.; Jiang, T.; Hou, L.H.; Li, J.X.; Yang, B.F.; Wang, L.; Wang, W.J., et al. Immunogenicity and safety of a recombinant adenovirus type-5vectored COVID-19 vaccine in healthy adults aged 18 years or older: a randomised, doubleblind, placebo-controlled, phase 2 trial. Lancet 2020, 396, 479-488, doi:10.1016/S01406736(20)31605-6.

75. Folegatti, P.M.; Ewer, K.J.; Aley, P.K.; Angus, B.; Becker, S.; Belij-Rammerstorfer, S.; Bellamy, D.; Bibi, S.; Bittaye, M.; Clutterbuck, E.A., et al. Safety and immunogenicity of the ChAdOx1 nCoV-19 vaccine against SARS-CoV-2: a preliminary report of a phase $1 / 2$, single-blind, randomised controlled trial. Lancet 2020, 396, 467-478, doi:10.1016/S0140-6736(20)31604-4.

76. Rakhra, K.; Abraham, W.; Wang, C.; Moynihan, K.D.; Li, N.; Donahue, N.; Baldeon, A.D.; Irvine, D.J. Exploiting albumin as a mucosal vaccine chaperone for robust generation of lungresident memory $\mathrm{T}$ cells. Science Immunology 2021, 6, eabd8003, doi:10.1126/sciimmunol.abd8003.

77. van Doremalen, N.; Purushotham, J.; Schulz, J.; Holbrook, M.; Bushmaker, T.; Carmody, A.; Port, J.; Yinda, K.C.; Okumura, A.; Saturday, G., et al. Intranasal ChAdOx1 nCoV19/AZD1222 vaccination reduces shedding of SARS-CoV-2 D614G in rhesus macaques. bioRxiv 2021, 10.1101/2021.01.09.426058, doi:10.1101/2021.01.09.426058.

78. Bui, H.H.; Sidney, J.; Dinh, K.; Southwood, S.; Newman, M.J.; Sette, A. Predicting population coverage of T-cell epitope-based diagnostics and vaccines. BMC Bioinformatics 2006, 7, 153, doi:10.1186/1471-2105-7-153.

79. Fukami-Kobayashi, K.; Shiina, T.; Anzai, T.; Sano, K.; Yamazaki, M.; Inoko, H.; Tateno, Y. Genomic evolution of MHC class I region in primates. Proc Natl Acad Sci U S A 2005, 102, 9230-9234, doi:10.1073/pnas.0500770102. 


\section{Supplemental Materials}

\section{Figure S1}
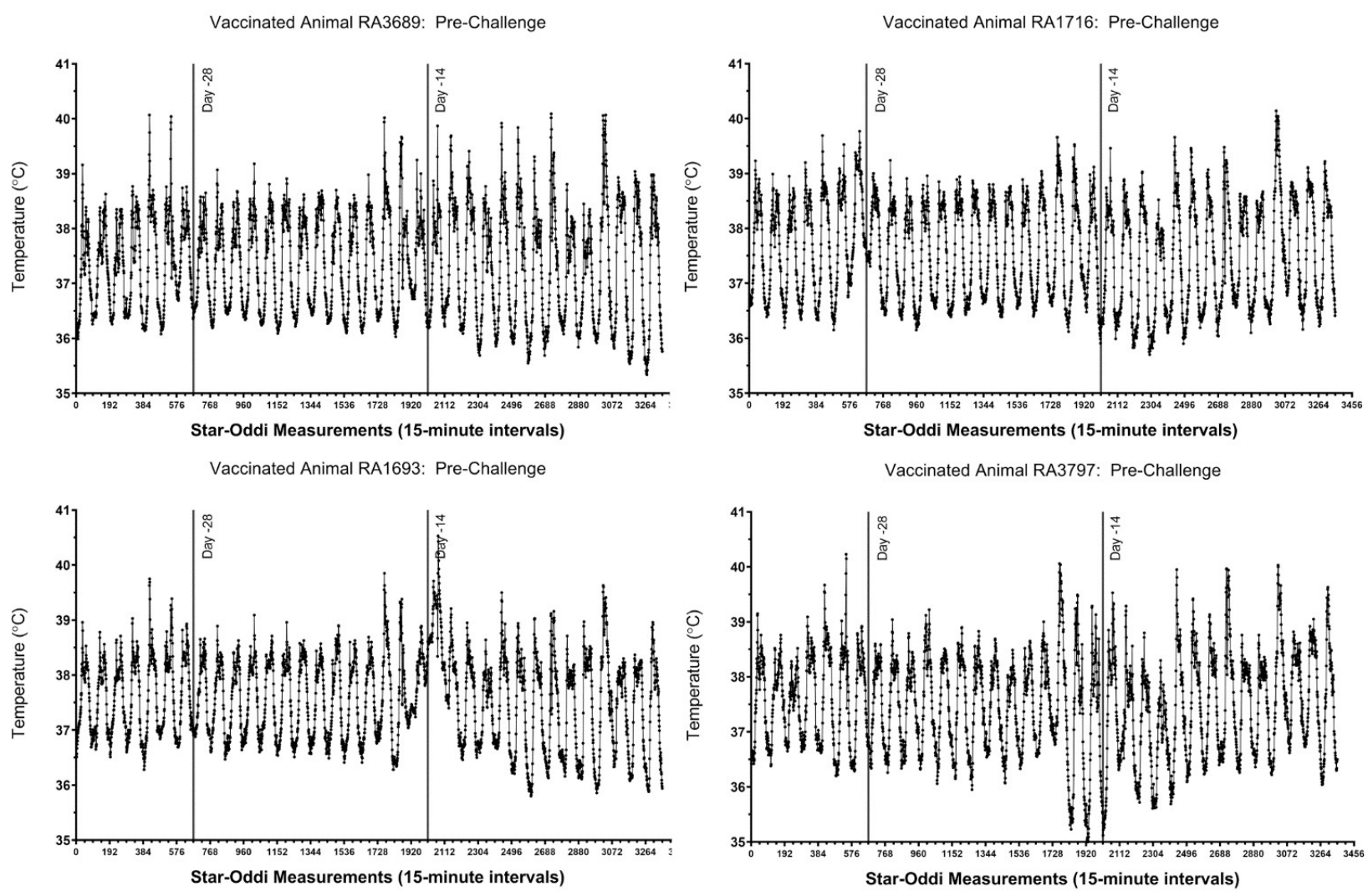

Supplemental Data, Figure S1 legend. Core body temperature alterations in vaccinated macaques prior to SARS-CoV-2 challenge. For each animal, 35 days of pre-challenge temperature measurements are shown. Each tick on the x-axis represents 12 hours or 48 individual logger measurements. 

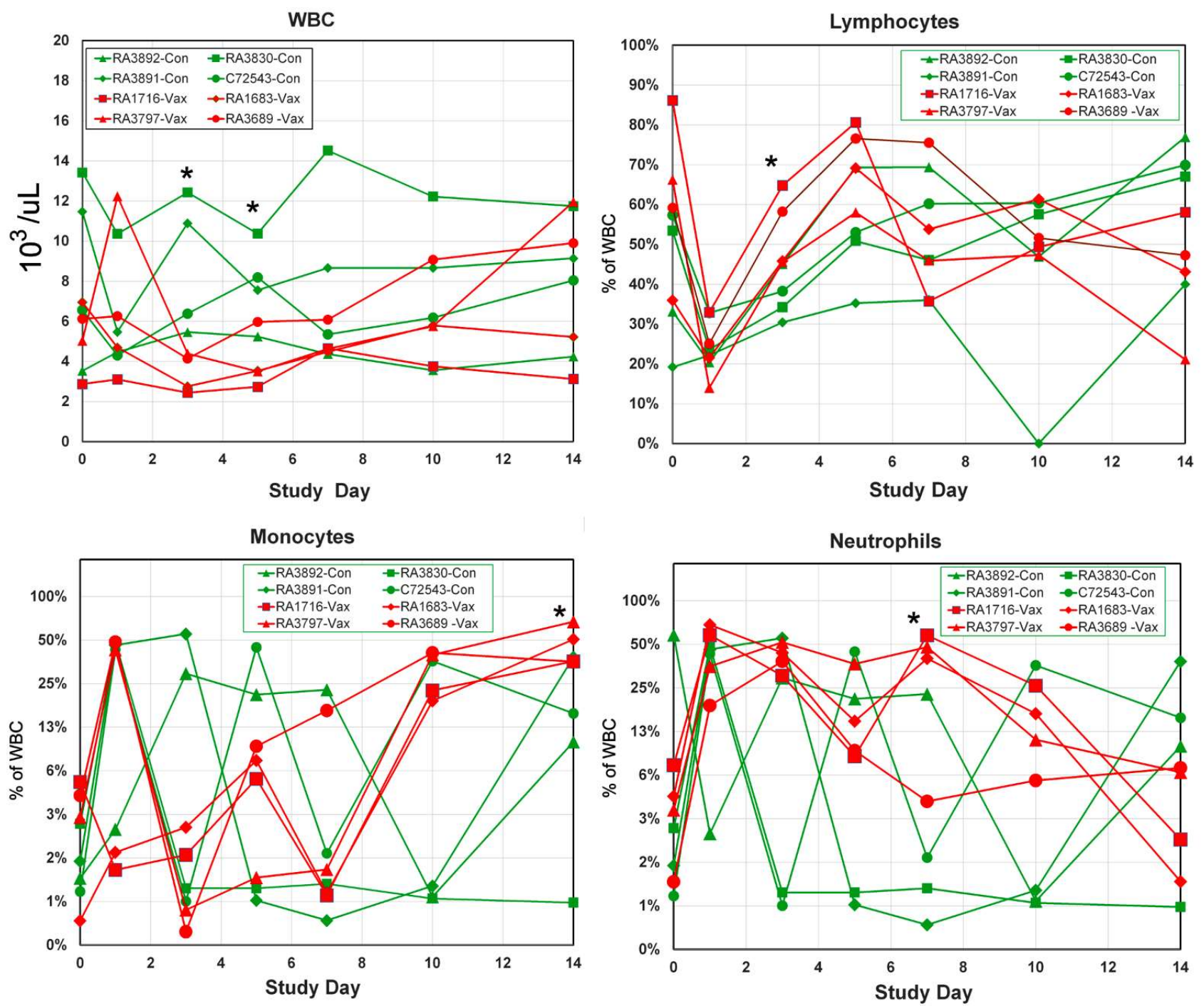

Supplemental Data, Figure S2 Legend. Hematological analysis in control and vaccinated macaques challenged with SARS-CoV-2. The counts of white blood cells (WBC) (upper left panel), the percent of lymphocytes in WBC (upper right panel), the percent of monocytes in the WBC (lower left panel), and the percent of neutrophils in the WBC (lower right panel) were analyzed. An asterisk indicates a statistically significant difference $(p<0.05)$ between control and vaccinated macaques by Students t-test. 


\section{Figure S3}

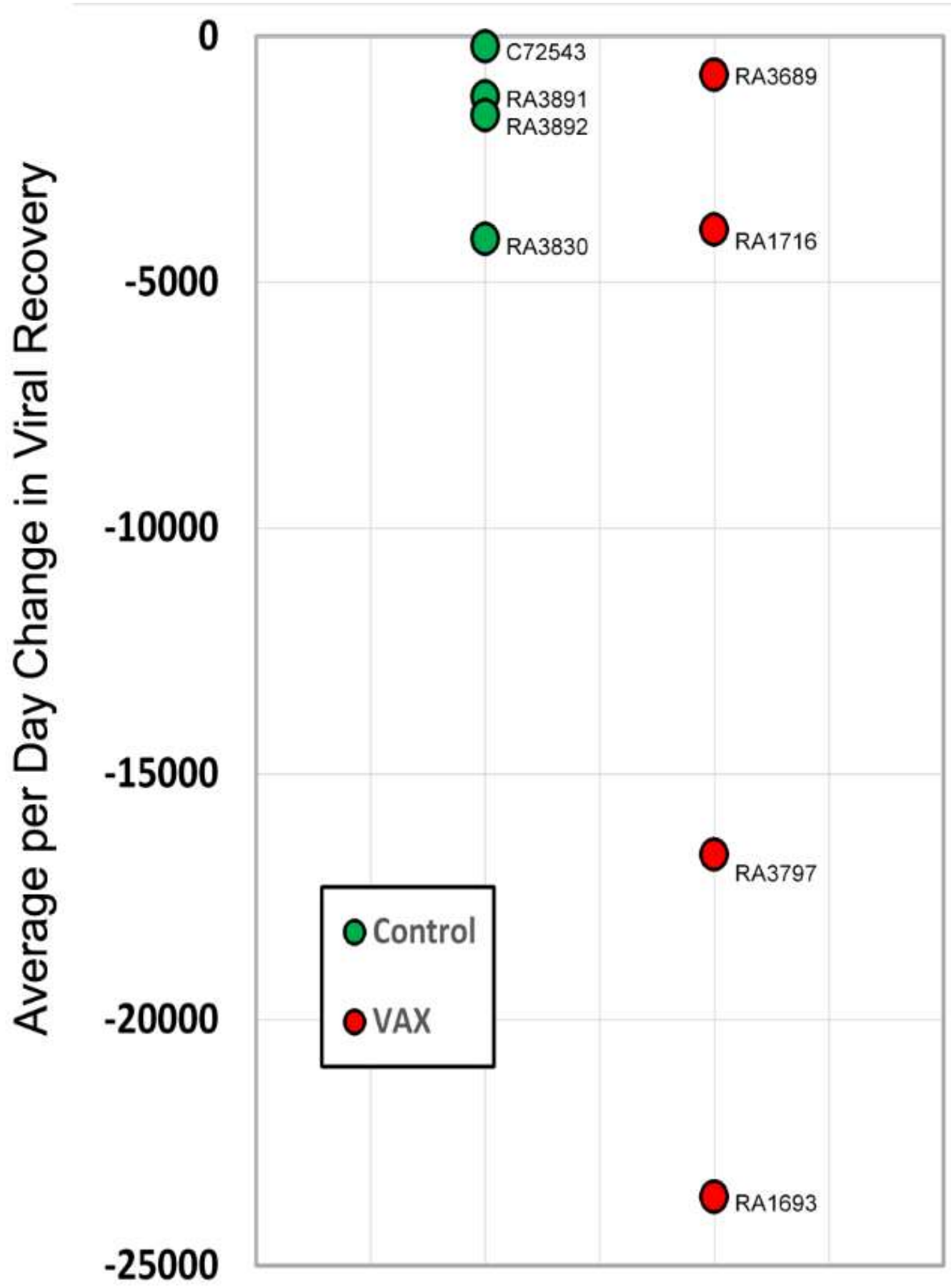

Supplemental Data, Figure S3 Legend. Viral clearance rates in control and vaccinated SARS CoV2 challenged macaques. From the total viral loads measurements in nasal swab samples from SARSCoV-2 challenged macaques, the daily viral clearance rates (i.e. TCID $50 / m L$ day n- $\operatorname{minus}$ TCID $50 / m L$ day n) were calculated and averaged over a nine-day period. Red symbols are vaccinated macaques subjects, control unvaccinated macaque subjects are shown in green symbols. 

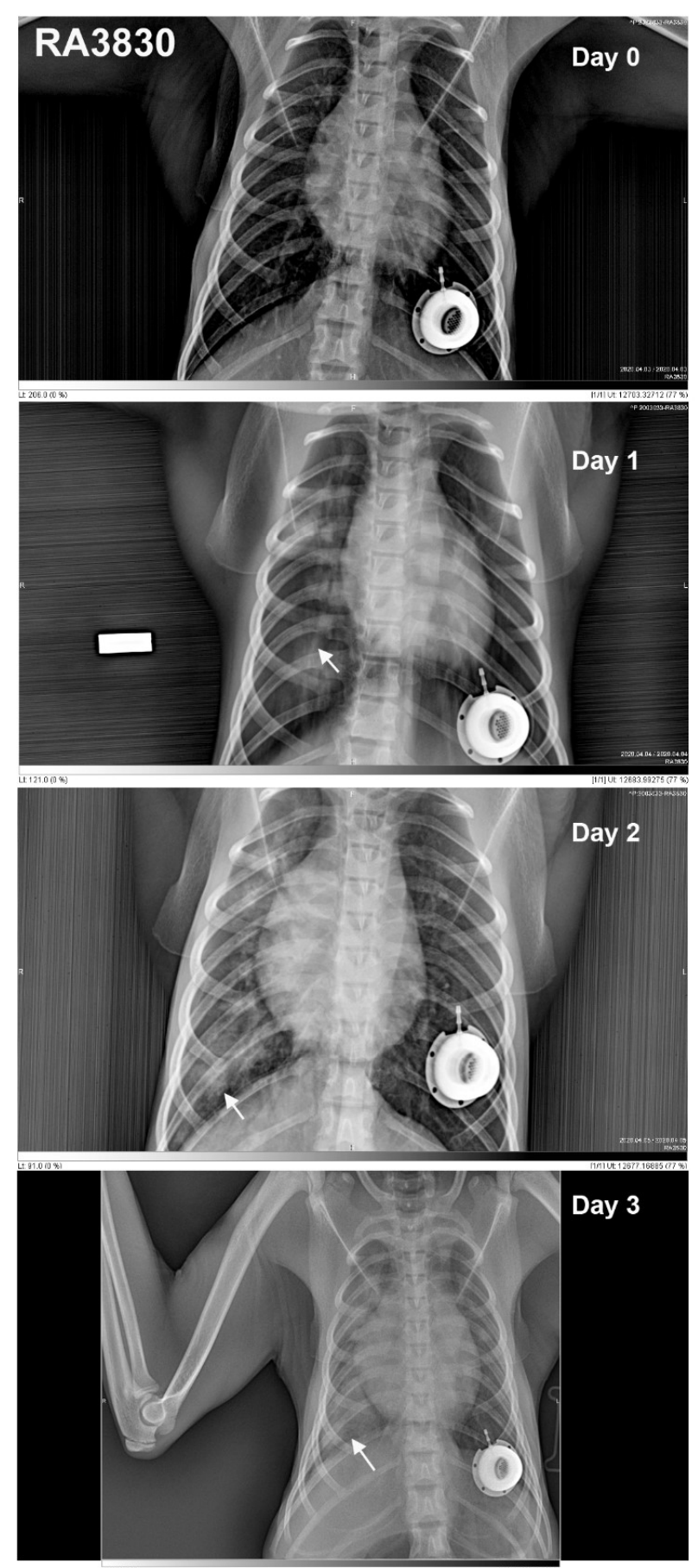

Figure S4
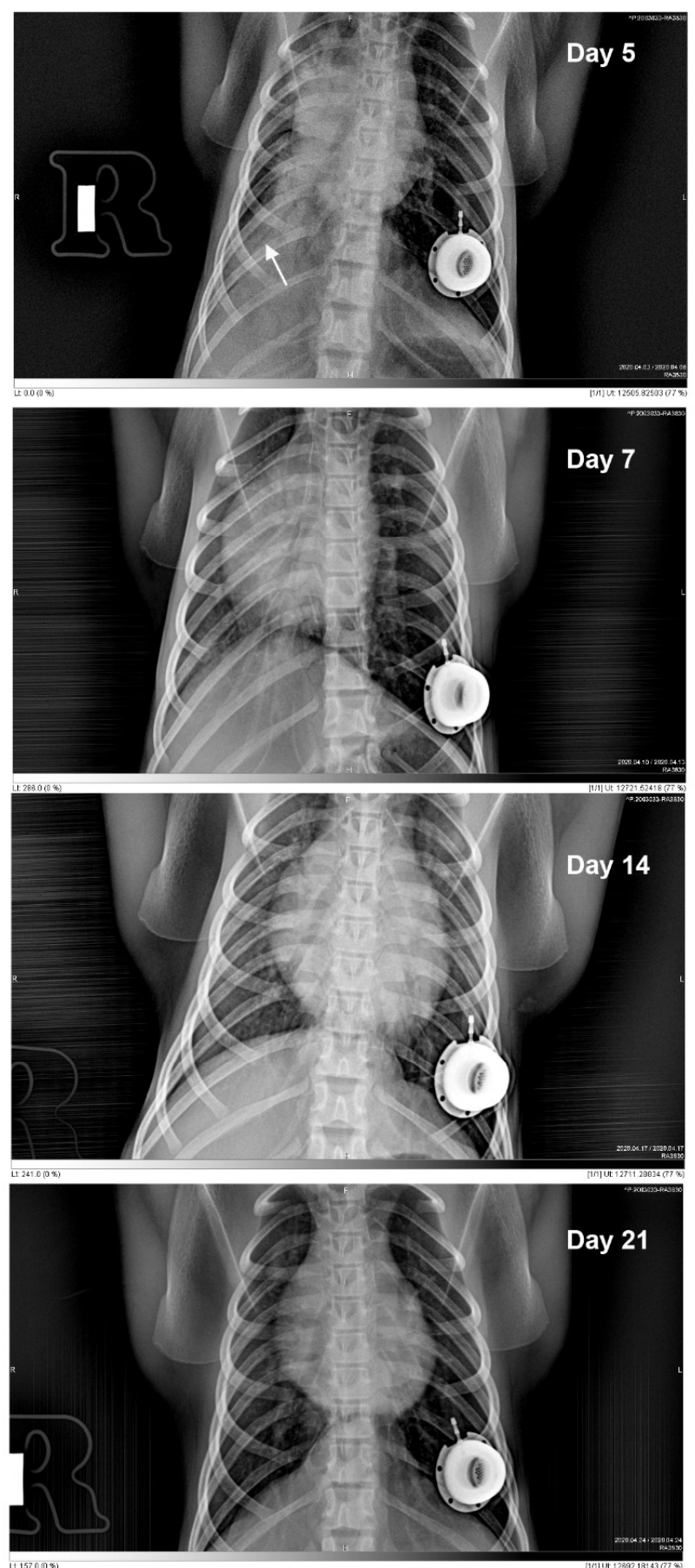

Supplemental Data, Figure S4 legend. Chest radiographs of control rhesus macaque RA3830 following SARS-CoV-2 challenge. As shown, this animal demonstrated a progression of pulmonary infiltrates during the acute period (Days 2-5) of disease post-challenge which resolved by study termination (Day 21). White arrows indicate areas of mild to moderate pulmonary infiltrates seen as ground glass consolidations. 

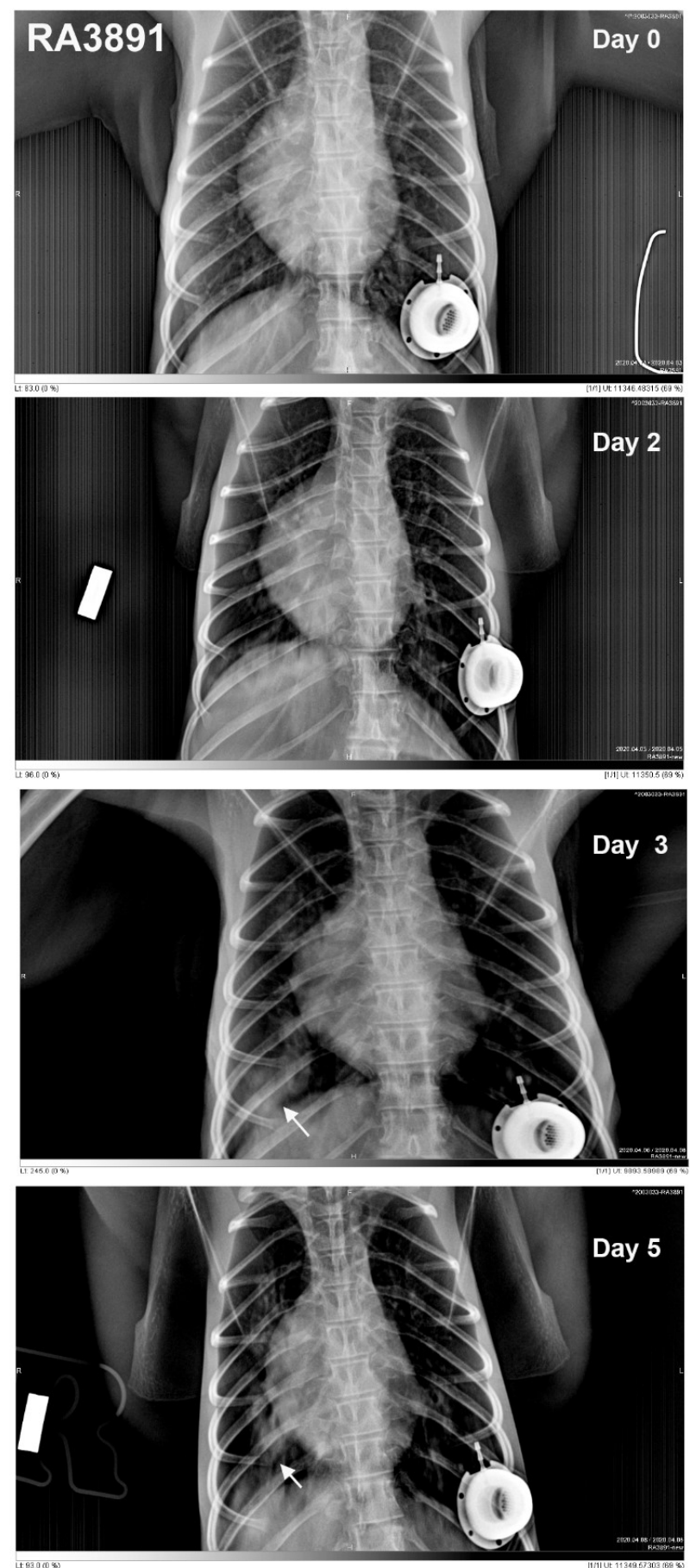
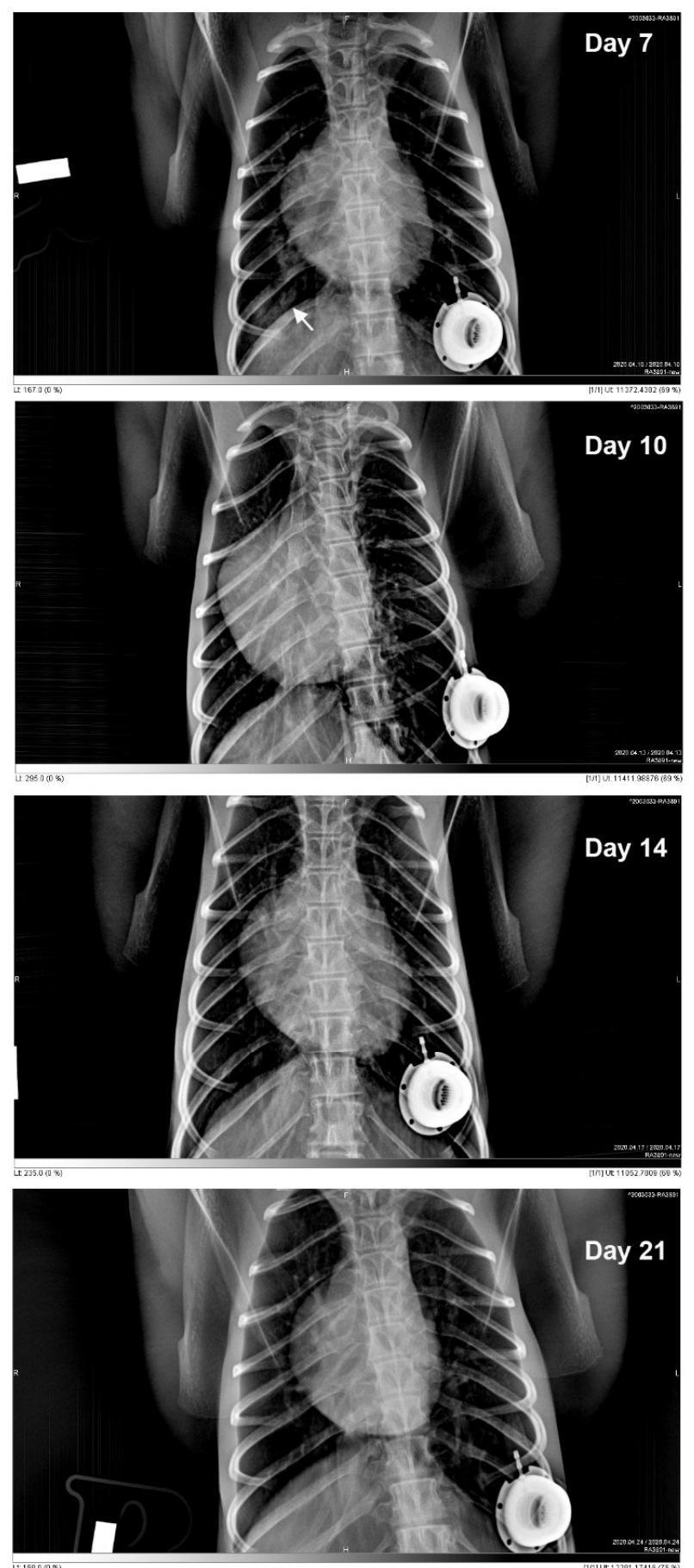

Supplemental Data, Figure S4 Legend. Chest radiographs of control rhesus macaque RA3891 following SARS-CoV-2 challenge. As shown, this animal demonstrated a progression of pulmonary infiltrates during the acute period (Days 3-7) of disease post-challenge which resolved by study termination (Day 21). White arrows indicate areas of mild to moderate pulmonary infiltrates seen as ground glass consolidations. 
bioRxiv preprint doi: https://doi.org/10.1101/2021.04.24.441228; this version posted April 26, 2021. The copyright holder for this preprint (which was not certified by peer review) is the author/funder, who has granted bioRxiv a license to display the preprint in perpetuity. It is made available under aCC-BY-ND 4.0 International license.
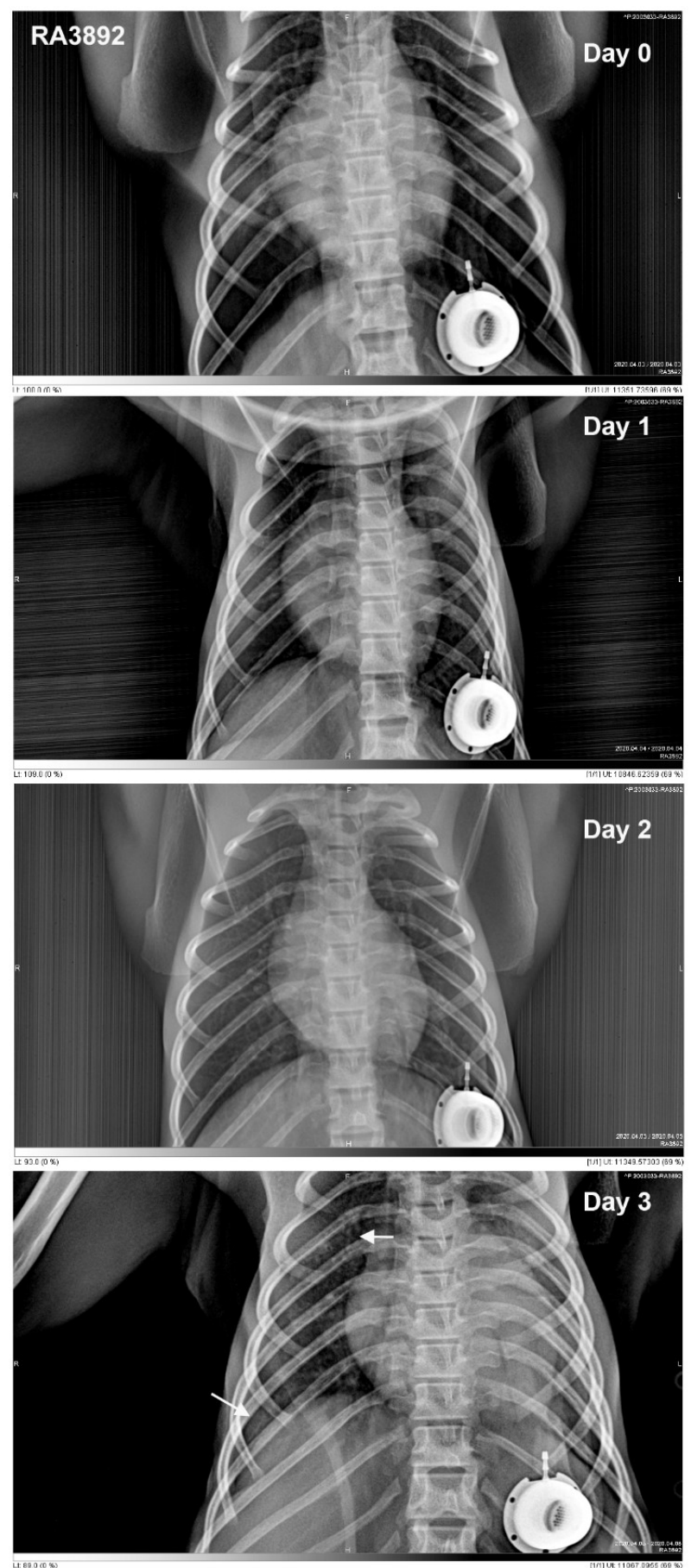
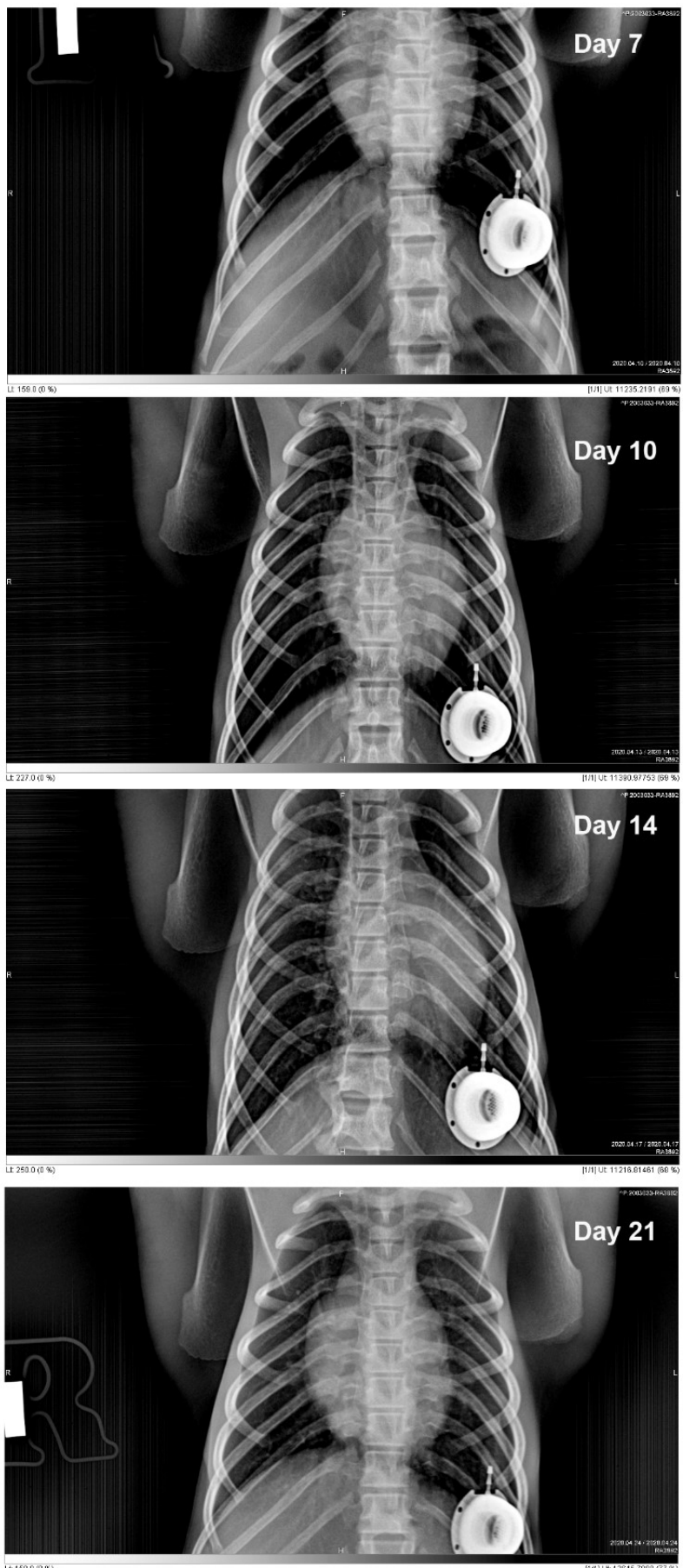

Supplemental Data, Figure S6 Legend. Chest radiographs of control rhesus macaque RA3892 following SARS-CoV-2 challenge. As shown, this animal demonstrated a progression of pulmonary infiltrates during the acute period (Day 3) of disease post-challenge which resolved by study termination (Day 21). White arrows indicate areas of mild to moderate pulmonary infiltrates seen as ground glass consolidations. 
bioRxiv preprint doi: https://doi.org/10.1101/2021.04.24.441228; this version posted April 26, 2021. The copyright holder for this preprint (which was not certified by peer review) is the author/funder, who has granted bioRxiv a license to display the preprint in perpetuity. It is made available under aCC-BY-ND 4.0 International license.
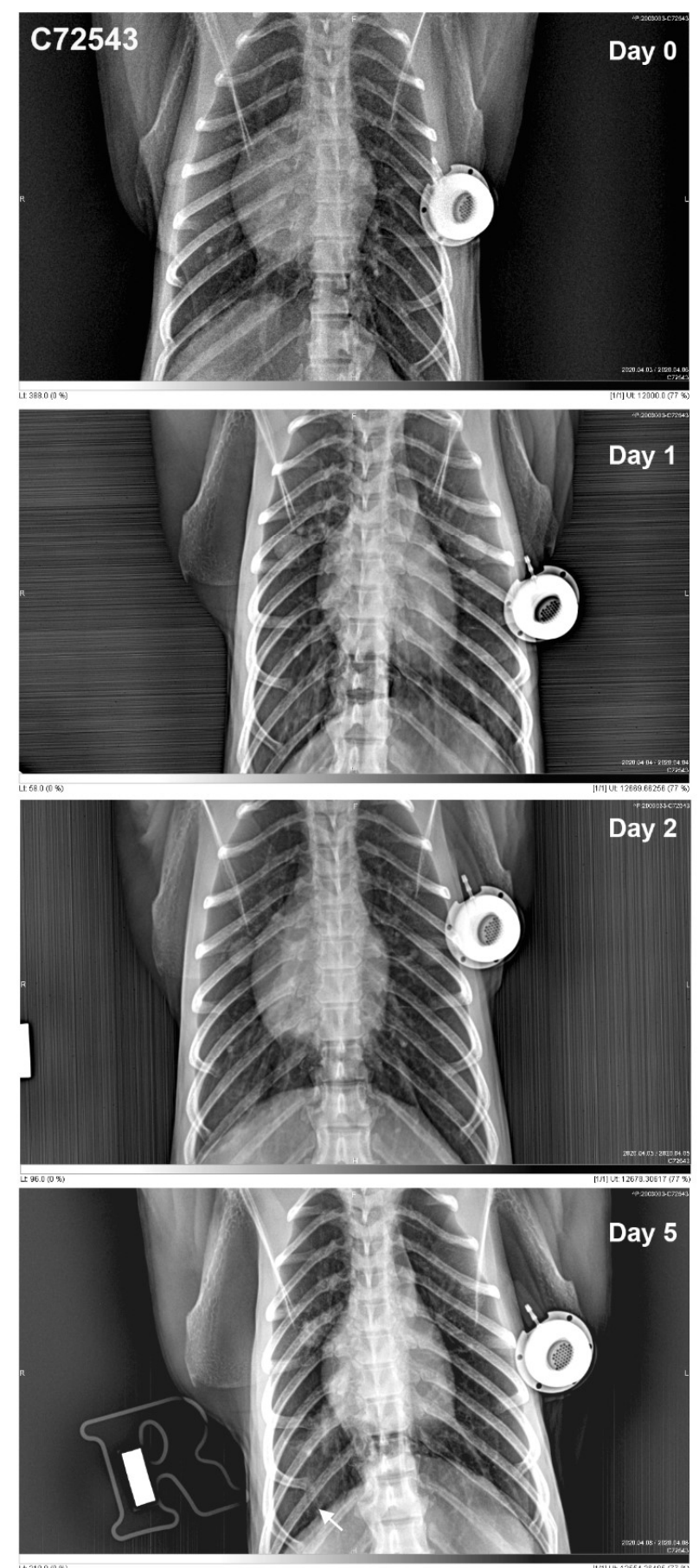

$(5 \ln 2004$
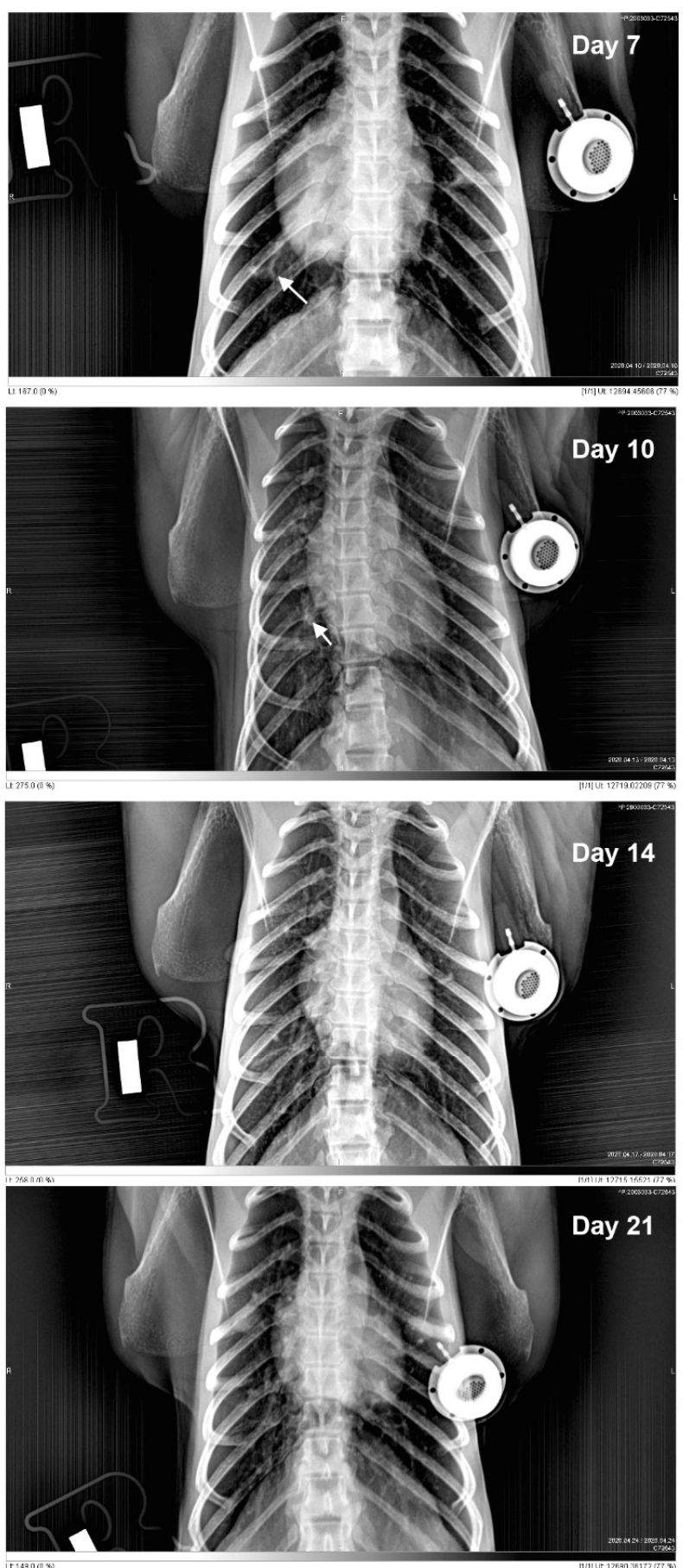

\section{Figure S7}

Supplemental Data, Figure S7 Legend. Chest radiographs of control cynomolgus macaque C72543 following SARS-CoV-2 challenge. As shown, this animal demonstrated a progression of pulmonary infiltrates 5-10 days post-challenge which resolved by study termination (Day 21). White arrows indicate areas of mild to moderate pulmonary infiltrates seen as ground glass consolidations. 
bioRxiv preprint doi: https://doi.org/10.1101/2021.04.24.441228; this version posted April 26, 2021. The copyright holder for this preprint (which was not certified by peer review) is the author/funder, who has granted bioRxiv a license to display the preprint in perpetuity. It is made available under aCC-BY-ND 4.0 International license.
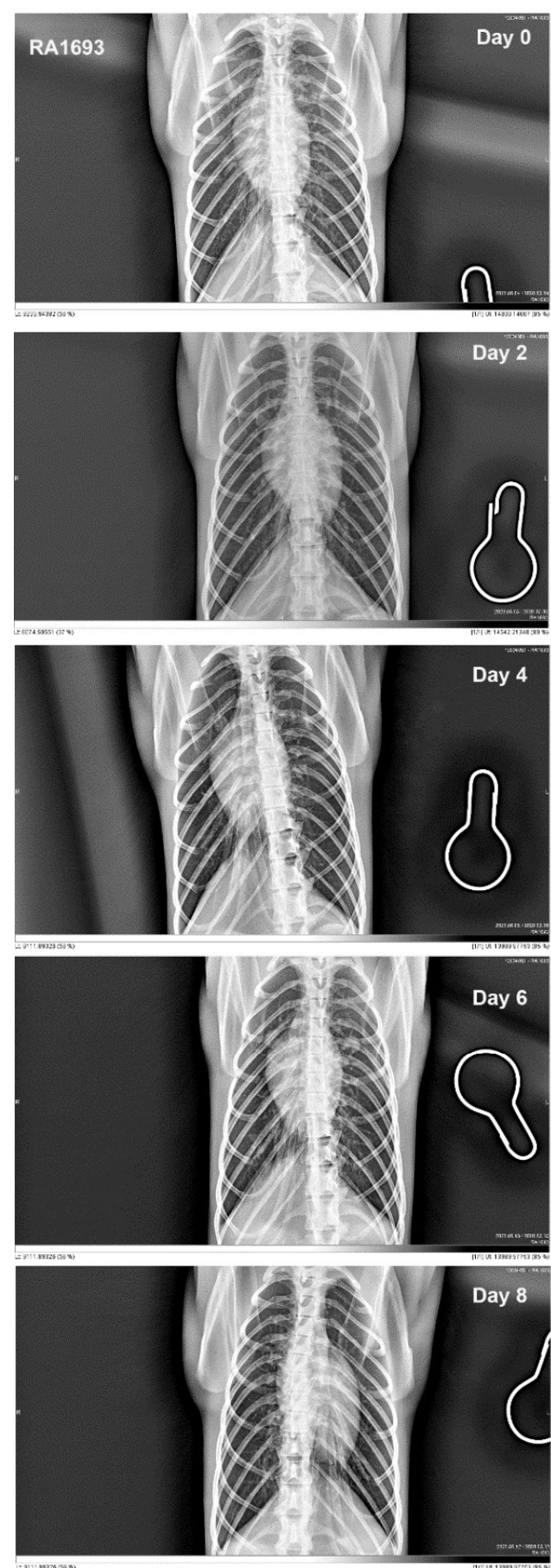
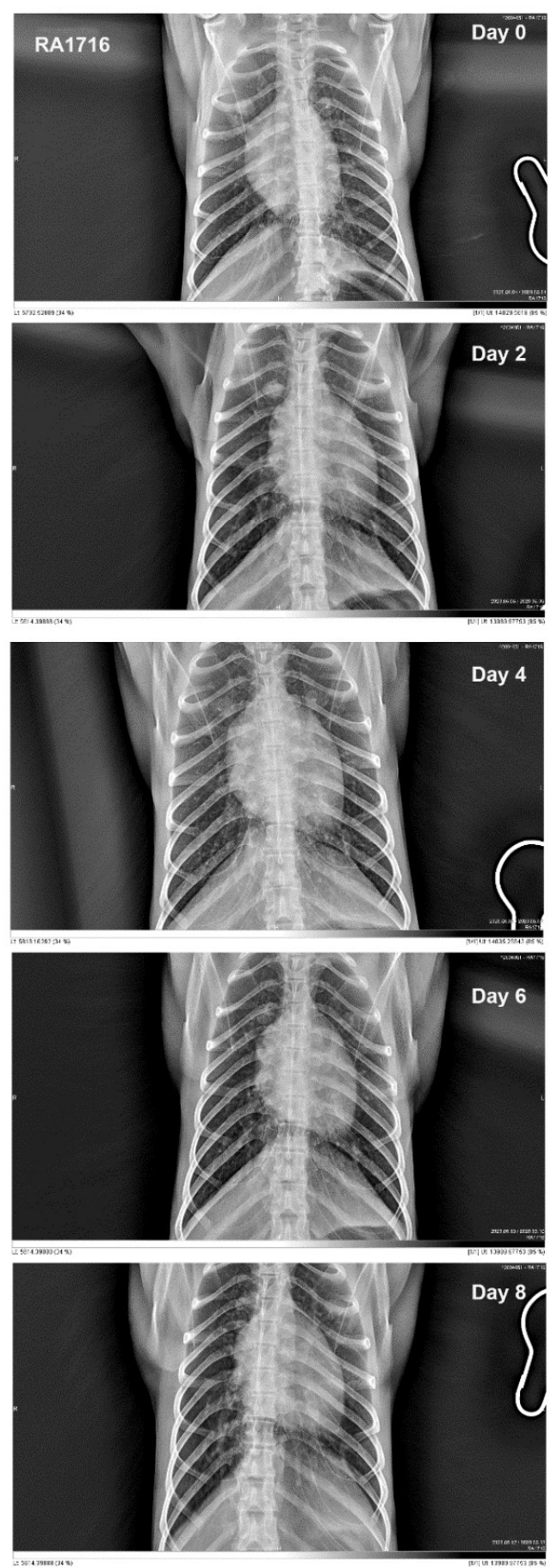

Supplemental Data, Figure S8 Legend. Chest radiographs of vaccinated rhesus macaques RA1693 and RA1716 following SARS-CoV-2 challenge. With the exception of increased reticulation relative to baseline, few abnormalities were observed in collected radiograph images. Note the absence of infiltrates or consolidation typically seen in the unvaccinated control population. 
bioRxiv preprint doi: https://doi.org/10.1101/2021.04.24.441228; this version posted April 26, 2021. The copyright holder for this preprint (which was not certified by peer review) is the author/funder, who has granted bioRxiv a license to display the preprint in perpetuity. It is made available under aCC-BY-ND 4.0 International license.
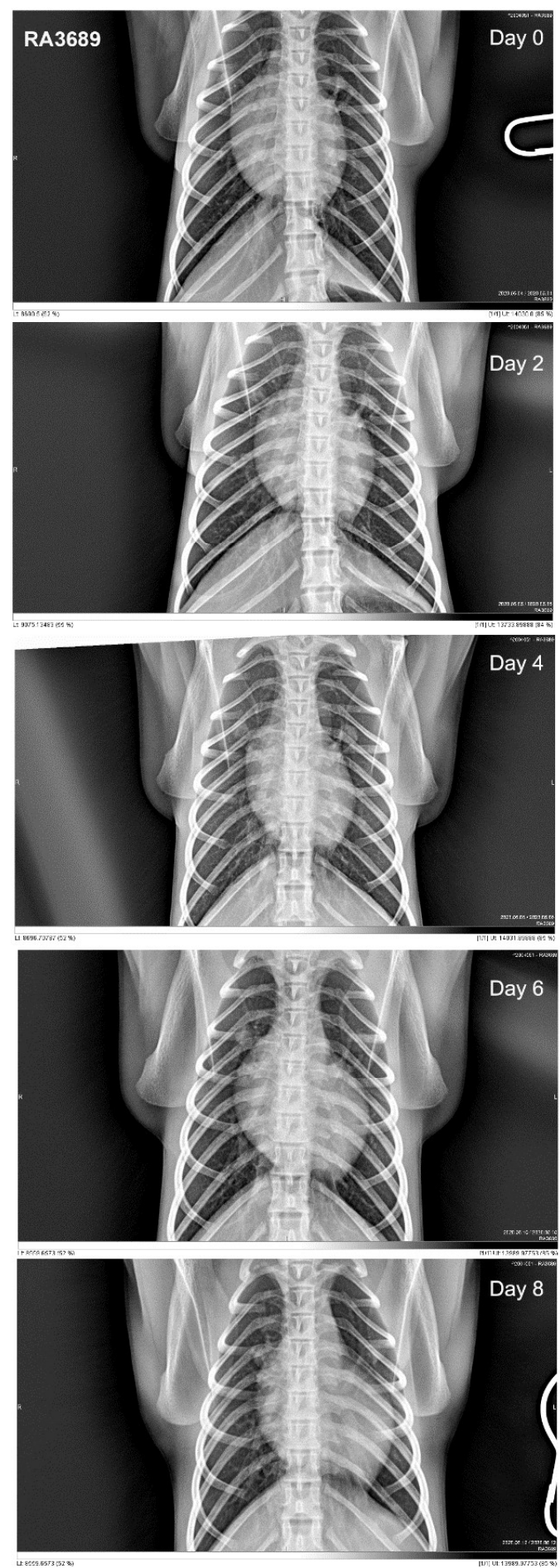
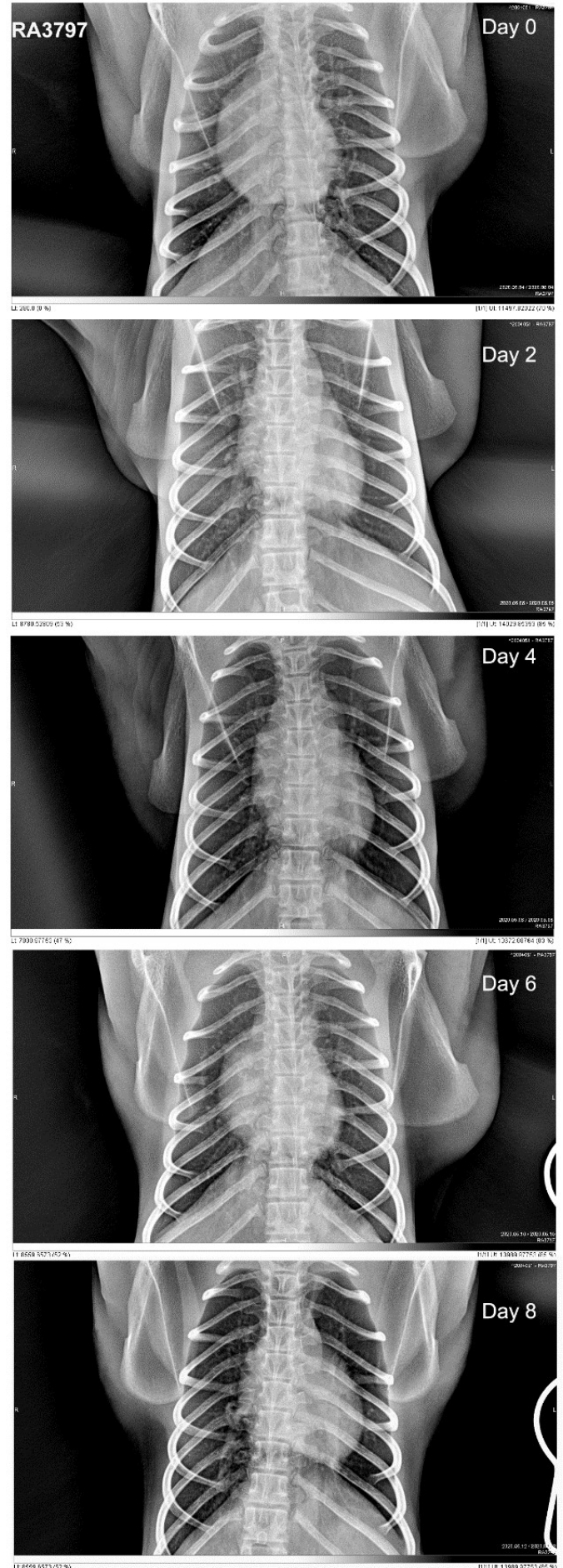

Supplemental Data, Figure S9 Legend. Chest radiographs of vaccinated rhesus macaques RA3689 and RA3797 following SARS-CoV-2 challenge. Radiographs are unremarkable, other than showing increased reticulation relative to baseline, appearing on days 2 through 4 , clearing on later imaging. In particular, note lack of focal infiltrates or consolidations. 
1003

\section{Figure S10}

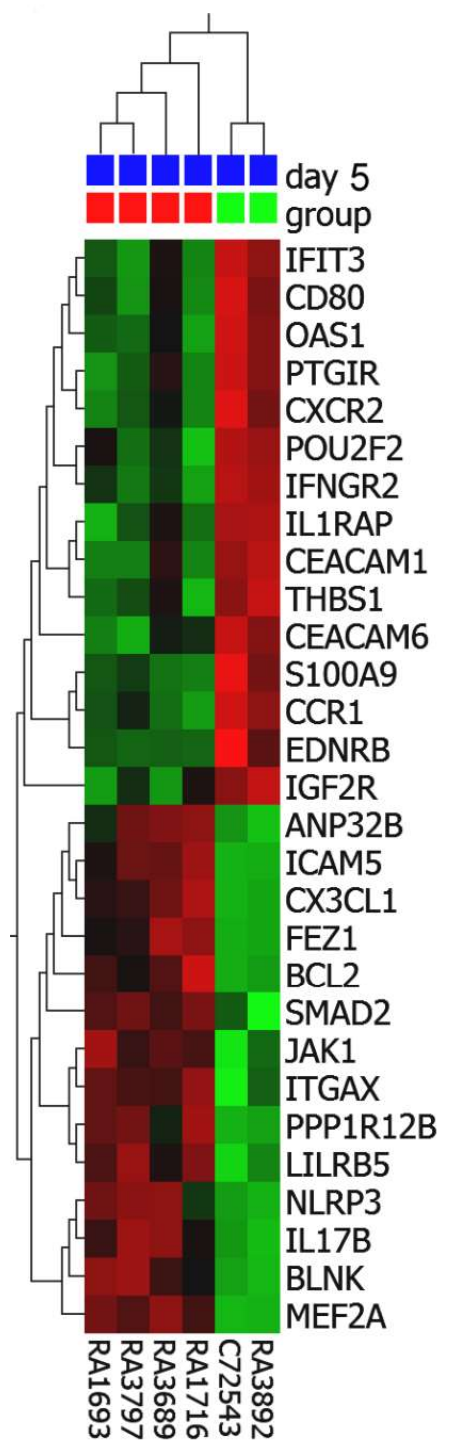

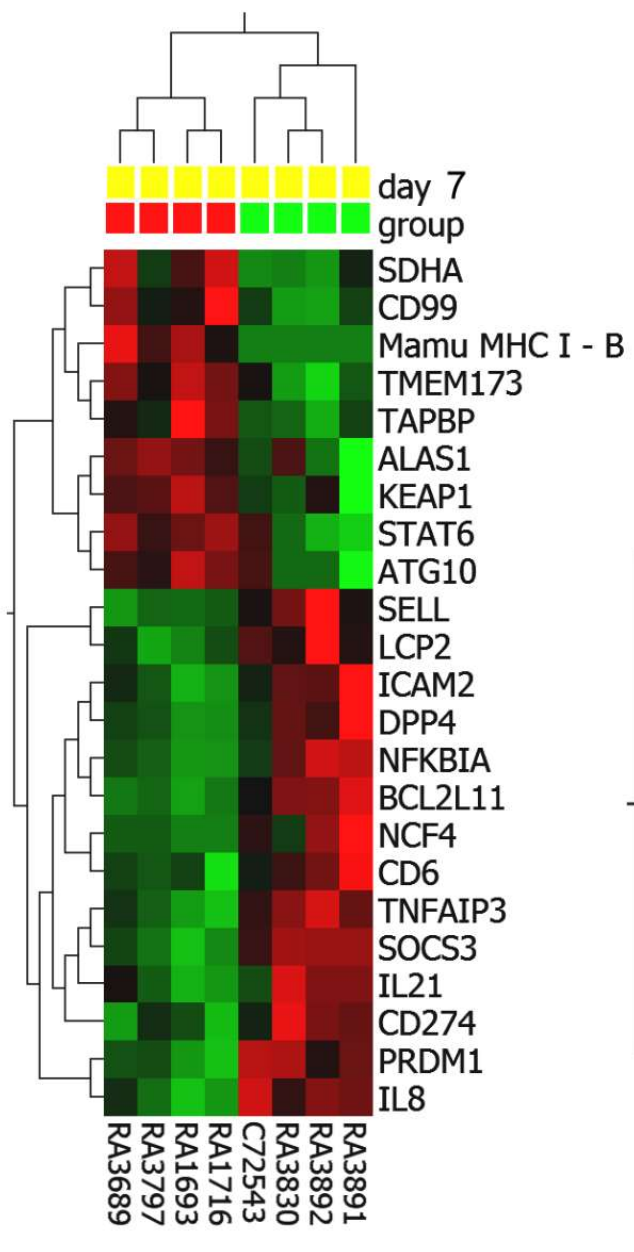
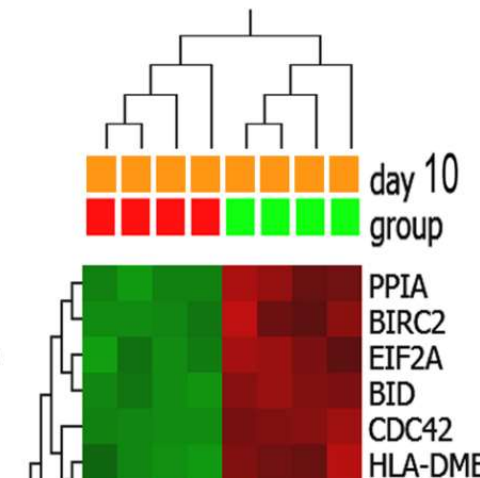

HLA-DMB

ANP32B

UBE2L3

LY96

CTSC

HLA-DRA

TYROBP

ATF2

KEAP1

ADGRE5

POLR2A

CASP2

MAPKAPK5

ABL1

TYK2

IL6R

HDAC3

G6PD

TOLLIP

SDHA

SHC1

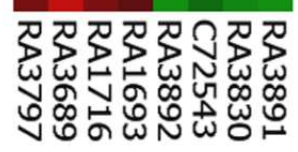

\section{Vaccinated macaques}

\section{Control macaques}

1004

1005

Supplemental Data, Figure S10. Hierarchical clustering of gene expression in BAL samples collected from control and vaccinated macaques on Day 5 (left panel), Day 7 (middle panel), and Day 10 (right panel). 5- and 7- days post SARS-CoV-2 challenge. Heatmap shows significantly $(\mathrm{p}<0.05)$ up-regulated (red) transcripts and down-regulated (green) transcripts from a total of 730 genes analyzed using the NanoString Non-Human Primate Immunology V2 Panel. 

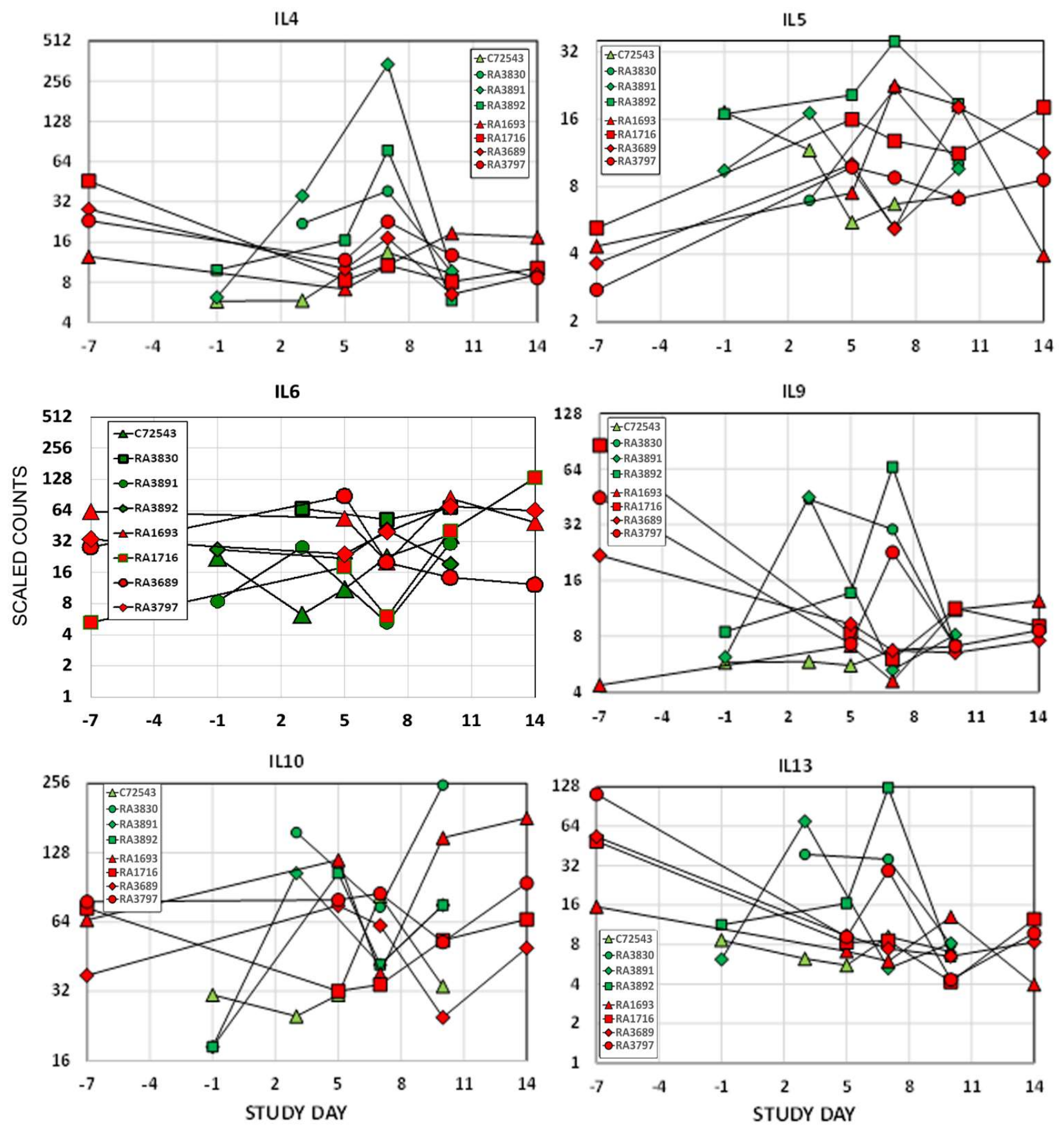

Supplemental Data, Figure S11 Legend. Intratracheal vaccination with the adjuvanted microsphere peptide vaccine did not promote the expression of $\mathrm{Th}_{2}$ type interleukin cytokine transcripts in collected BAL samples relative to levels measured in control macaques. BAL cell gene expression (shown as scaled counts on the y-axis) of cytokines associated with $\mathrm{Th}_{2} \mathrm{~T}$ cell responses were plotted by study day (x-axis) for each animal prior to and following the SARS-CoV-2 challenge. No statistically significant differences between control and vaccinated macaques were found. 


\section{Figure S12}
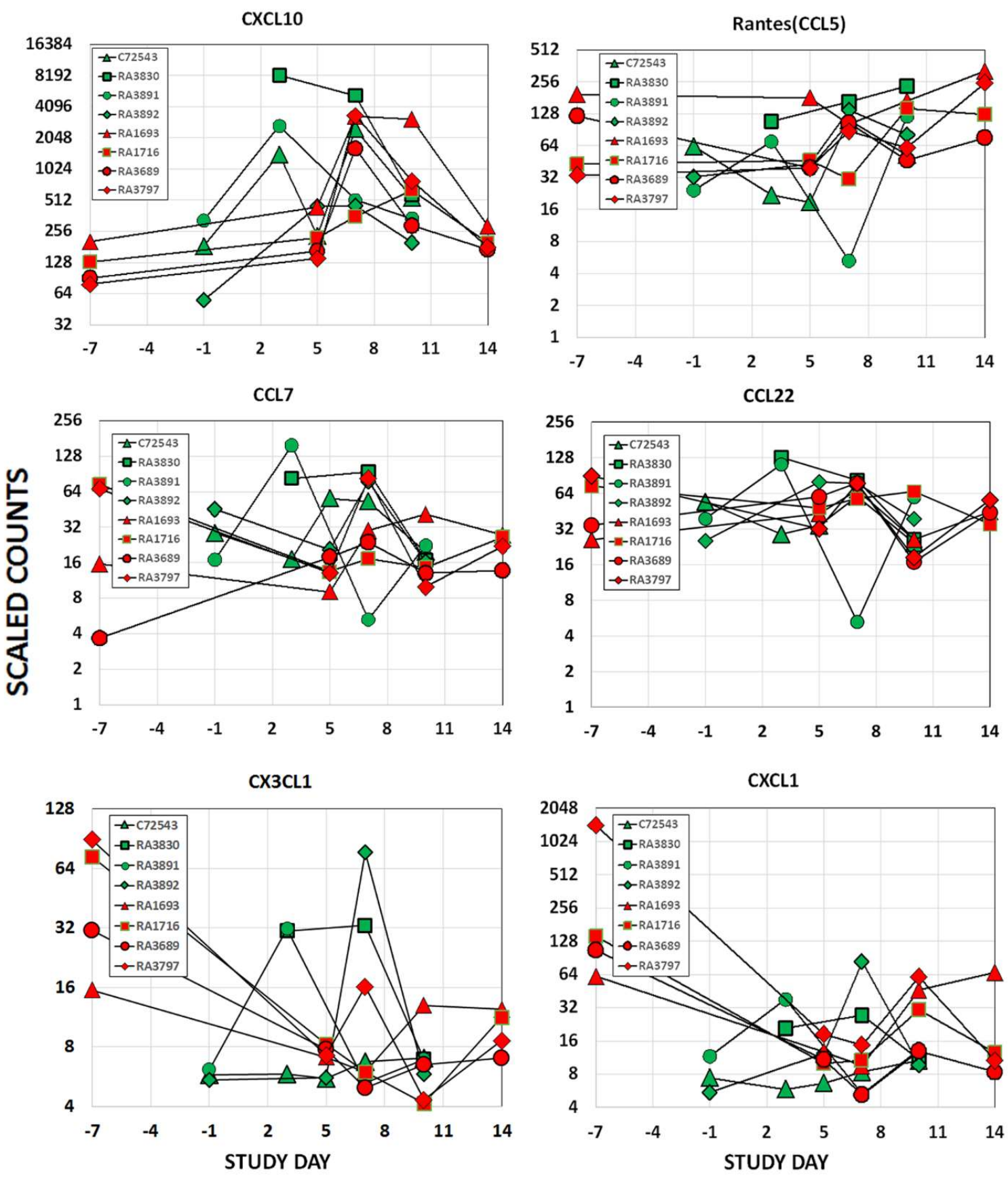

Supplemental Data, Figure S12. Intratracheal vaccination with the adjuvanted microsphere peptide vaccine did not promote the expression of Th2 type interleukin cytokine transcripts in collected BAL samples relative to levels measured in control macaques. BAL cell gene expression (shown as scaled counts on the y-axis) of cytokines associated with $\mathrm{Th}_{2} \mathrm{~T}$ cell responses were plotted by study day (x-axis) for each animal prior to and following the SARS-CoV-2 challenge. No statistically significant differences between control and vaccinated macaques were found. 


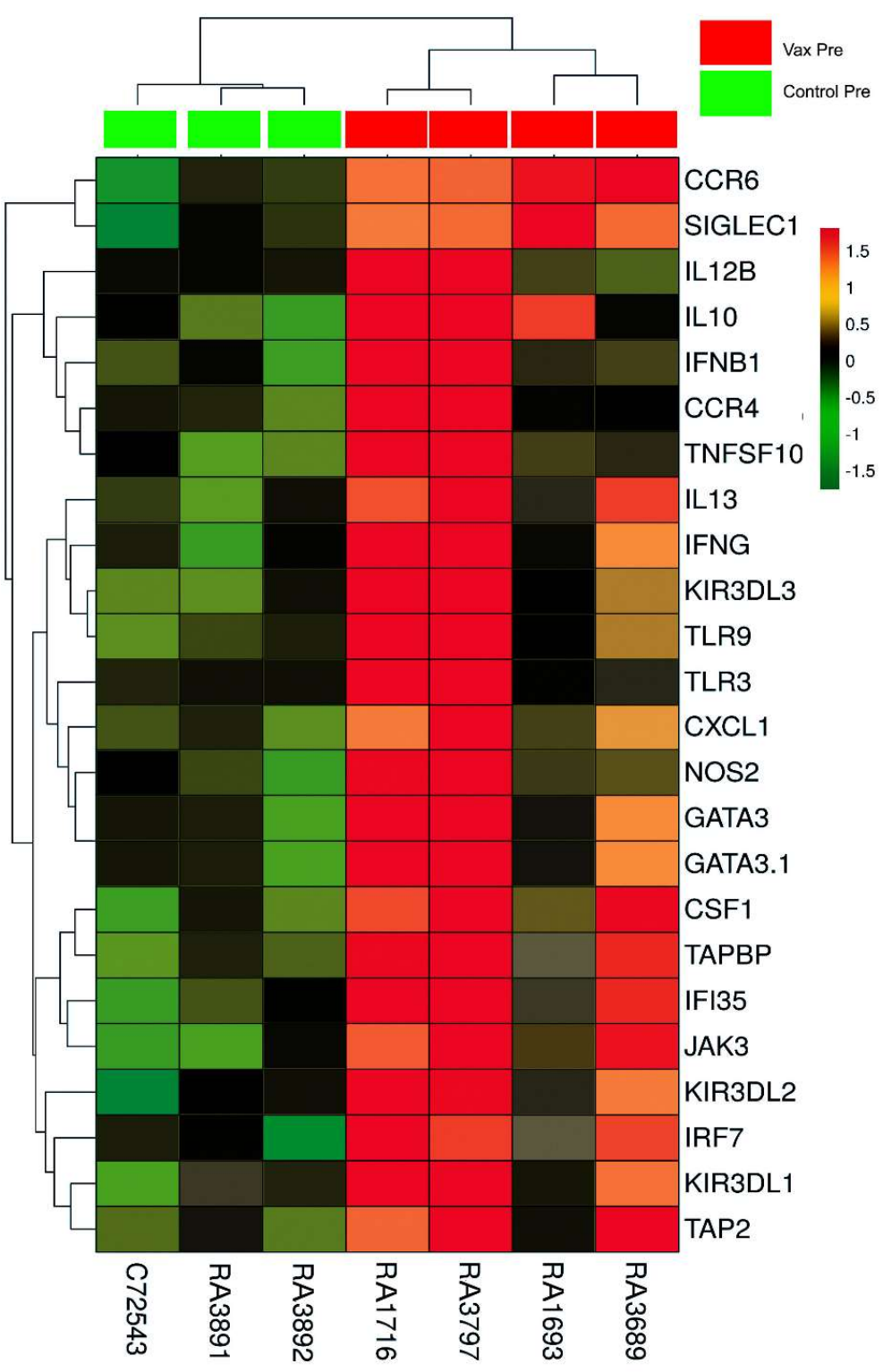

Supplemental Data, Figure S13 Legend. Hierarchical clustering of adjuvant-related transcript expression in BAL samples collected from control and vaccinated macaques prior to virus challenge (indicated as Control Pre and Vax Pre). Gene expression analysis identified differentially regulated genes in BAL samples obtained on Day - 1 from control animals and Day -7 from vaccinated macaques. Heatmap shows significant $(\mathrm{p}<0.05)$ differential expression of a series of genes that had previously been identified (see main text) as being regulated by adjuvants alone. Up-regulated (red); down-regulated (green). Macaque RA 3830 was not sampled on day - 1. 
Figure S14

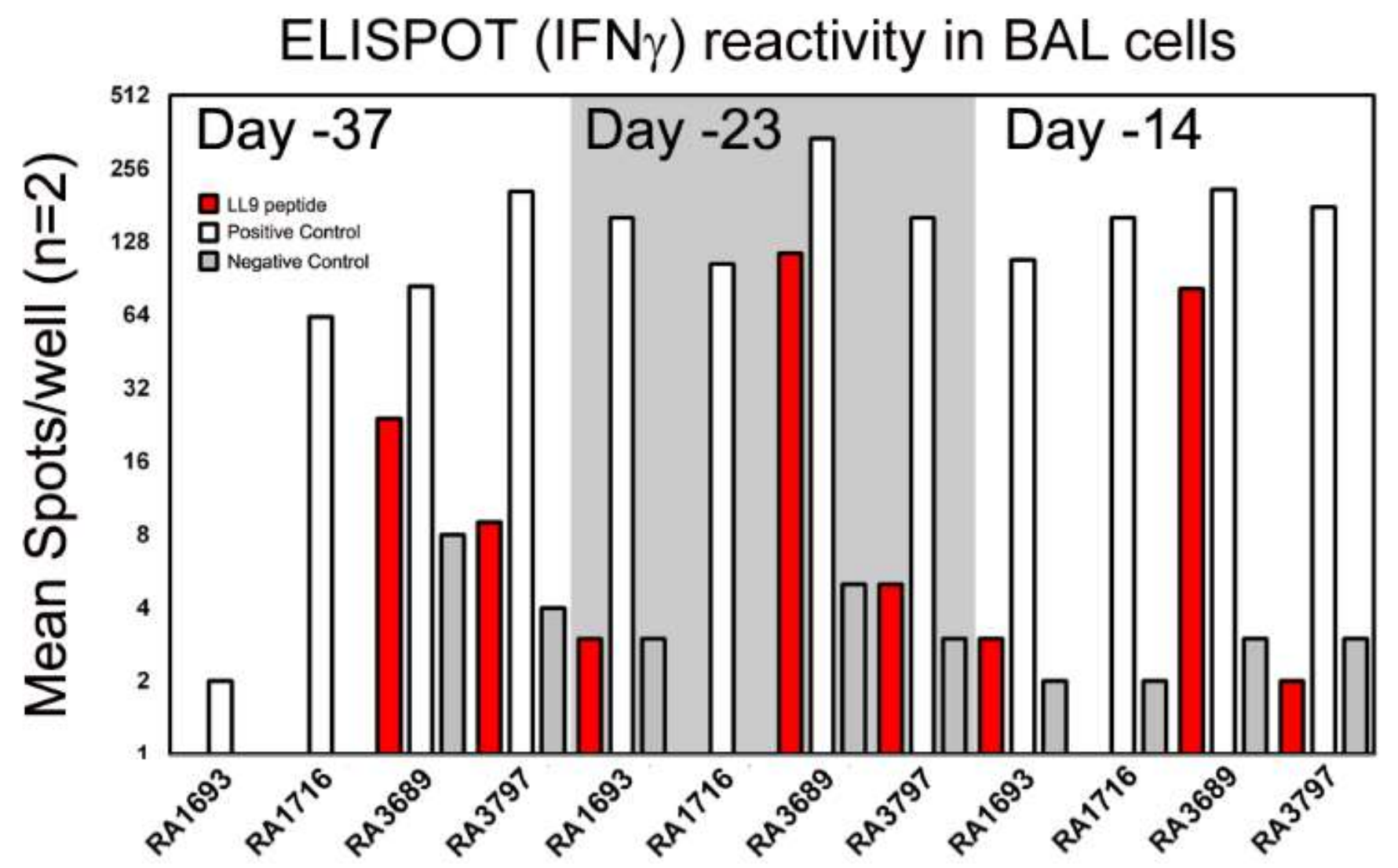

1042

1043

1044

1045

1046

Supplemental Data, Figure S14 Legend. Immunoreactivity of BAL-associated cells from vaccinated macaques to immunizing peptides prior to SARS-CoV-2 challenge. Dates shown are assay date rather than sampling date. Concanavlin A was used as a positive control. 


\section{Supplemental Materials}

\section{Supplemental data -Table S1A and S1B}

\begin{tabular}{|c|c|c|c|c|c|c|c|c|c|c|c|}
\hline \multicolumn{12}{|c|}{ Supplemental Table S1A } \\
\hline \multirow{2}{*}{$\begin{array}{l}\text { CTL epitope } \\
\text { HLA coverage }\end{array}$} & \multicolumn{10}{|c|}{ HLA allele (genotypic frequency \% world) } & \multirow{2}{*}{$\begin{array}{l}\text { Aggregate } \\
\text { HLA Class I } \\
\text { Coverage \% } \\
\end{array}$} \\
\hline & $\begin{array}{l}\text { HLA } \\
A^{*} 01: 01 \\
(10.09)\end{array}$ & 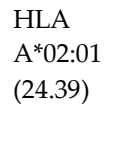 & $\begin{array}{l}\text { HLA } \\
A^{*} 03: 01 \\
(9.77)\end{array}$ & $\begin{array}{l}\text { HLA } \\
A^{*} 11: 01 \\
(8.99)\end{array}$ & 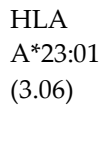 & $\begin{array}{l}\text { HLA } \\
A^{*} 24: 02 \\
(12.59)\end{array}$ & $\begin{array}{l}\text { HLA } \\
A^{*} 29: 02 \\
(2.18)\end{array}$ & $\begin{array}{l}\text { HLA } \\
A^{*} 30: 02 \\
(1.36)\end{array}$ & $\begin{array}{l}\text { HLA } \\
A^{* 31: 01} \\
(3.02)\end{array}$ & $\begin{array}{l}\text { HLA } \\
A^{*} 68: 0 \\
1 \\
(3.29)\end{array}$ & \\
\hline \multicolumn{12}{|l|}{ Epitope } \\
\hline LSPRWYFYY & +1 & - & - & + & + & + & + & + & + & - & 60.51 \\
\hline LLLDRLNQL & - & + & - & - & - & - & - & - & - & - & 39.08 \\
\hline КTFPРТЕРК & - & - & + & + & - & - & - & - & + & + & 40.03 \\
\hline GMSRIGMEV & - & + & - & - & - & - & - & - & - & - & 39.08 \\
\hline ASAFFGMSR & - & - & + & + & - & - & - & - & + & + & 40.03 \\
\hline QQQGQTVTK & - & - & - & + & - & - & - & - & + & - & \\
\hline Epitope Count & 1 & 2 & 2 & 4 & 1 & 1 & 1 & 1 & 4 & 2 & $91.51^{2}$ \\
\hline
\end{tabular}

Notes: 1. + Indicates positive in-vitro assays for MHC binding and/or T-cell recognition [36]. 2. Calculated as previously described[78]

\begin{tabular}{|c|c|c|c|c|c|c|c|}
\hline \multicolumn{8}{|c|}{ Supplemental Table S1B } \\
\hline \multicolumn{8}{|c|}{ Rhesus Mamu MHC Class I coverage - predicted binding } \\
\hline NHP Subject & R16931 & \multicolumn{2}{|c|}{ R1716 } & \multicolumn{2}{|l|}{ R3689 } & \multicolumn{2}{|l|}{ R3797 } \\
\hline \multicolumn{8}{|l|}{ Epitope } \\
\hline LSPRWYFYY & & $A 7^{*} 01: 03$ & & & & $A 1^{*} 002: 02$ & $\mathrm{~B}^{*} 068: 01(\mathrm{WB})$ \\
\hline \multirow[t]{2}{*}{ LLLDRLNQL } & $A 1^{*} 026: 01$ & $\begin{array}{l}\text { B:086:01 } \\
(\mathrm{WB})\end{array}$ & & $A 1^{*} 026: 01$ & $\mathrm{~B}^{*} 056: 01(\mathrm{WB})$ & $\mathrm{B}^{*} 056: 01(\mathrm{WB})$ & $B^{*} 068: 01(\mathrm{WB})$ \\
\hline & & & & $\mathrm{A} 1^{*} 004: 01(\mathrm{WB})$ & & $\mathrm{A} 1 * 004: 01(\mathrm{WB})$ & \\
\hline КTFPРTEPК & $\mathrm{B}^{*} 013: 01(\mathrm{SB})$ & $B^{*} 083: 01$ & $\begin{array}{l}\text { B:086:01 } \\
(\mathrm{WB})\end{array}$ & $B^{*} 066: 01$ & & $B^{*} 066: 01$ & \\
\hline GMSRIGMEV & $A 1^{*} 026: 01$ & & & $A 1^{*} 026: 01$ & & & \\
\hline ASAFFGMSR & $\mathrm{B}^{*} 013: 01(\mathrm{WB})$ & $B^{*} 083: 01$ & & $B^{*} 066: 01$ & & $B^{*} 066: 01$ & \\
\hline QQQGQTVTK & $B^{*} 013: 01(S B)$ & & & & & & \\
\hline
\end{tabular}

Notes: 1. A typical rhesus MHC haplotype may contain two or three expressed Mamu-A genes, and up to nineteen distinct Mamu-B-like loci[79], 2. Mamu MHC in italics are predicted to bind based on HLA homology and in-vitro analysis [40]. 3. Mamu MHC in regular font are predicted to bind based on NetMHCpan 4.1, with a weak binder (WB) at top $2 \%$ percentile rank and strong binder (SB) at top $0.5 \%$ precentile rank. 